\title{
(9)
}

Juan José Otamendi García-Jalón*

\section{EFECTOS DEL VETO RUSO EN LAS EXPORTACIONES ESPAÑOLAS}

Las exportaciones españolas a Rusia, que habían ido ganado importancia desde 1993, han experimentado un retroceso en 2013 y 2014, en gran medida debido a las sanciones rusas a los productos agroalimentarios procedentes de países que, a su vez, habían sancionado a Rusia por su actuación en Crimea. Para el caso de España, los productos afectados representaron en 2013 el 0,14 por 100 del total de sus exportaciones. El estudio analiza cuáles son los subsectores afectados y su comportamiento exportador después del veto. A tenor de los datos, muchos de estos han sido capaces de encontrar otras salidas para sus productos, mientras que el resto ha experimentado una caída mayor a la que sería explicada por el veto ruso, lo que nos lleva a pensar que detrás de la caída de sus exportaciones hay otras razones.

Palabras clave: comercio exterior, balanza agroalimentaria, sanciones comerciales, Rusia.

Clasificación JEL: F14, F51, Q17.

\section{Introducción}

Tras la desintegración de la URSS en 1991 y la aparición de Rusia como país independiente, las exportaciones españolas a este país experimentan un fuerte aumento, hasta el punto de terminar convirtiéndose en el $16^{\circ}$ destino de nuestras exportaciones en los años 2007, 2011 y 2012, con una cuota de mercado para los productos españoles del 1,2 por 100 del total de las importaciones rusas en los últimos años (menor que la cuota mundial de las exportaciones españolas, 1,6 por 100 en 2012), lo que nos convertía en su $21^{\circ}$ suministrador.

En agosto de 2014, la Unión Europea tomó una serie de medidas motivadas por la actuación rusa en Crimea, que tuvieron respuesta en forma de prohibición a la entrada al territorio ruso de productos

\footnotetext{
* Técnico Comercial y Economista del Estado.

Versión de mayo de 2015.
}

agrícolas, alimentos y materias primas originarios de los países que se unieron a la política de sanciones europea.

El objeto de este artículo es ver el efecto que han tenido estas prohibiciones en nuestras exportaciones. Para ello se examinará la evolución del comercio por sectores y subsectores hasta las sanciones y después de las mismas, para ver los efectos que han tenido en el sector agroalimentario, el efecto comparado en otros países de la UE y las medidas de compensación adoptadas.

\section{Evolución de las exportaciones españolas a Rusia hasta las sanciones}

Tras la disolución de la Unión Soviética en diciembre de 1991, España reconoció oficialmente a la Federación Rusa (27/12/1991). Para 1992, en las estadísticas aparece comercio tanto con la URSS como con Rusia, con lo que no puede $\triangleright$ 


\begin{tabular}{|c|c|c|c|c|c|c|c|c|}
\hline \multirow[b]{2}{*}{ Año } & \multicolumn{7}{|c|}{$\begin{array}{c}\text { CUADRO } 1 \\
\text { EVOLUCIÓN DE LAS EXPORTACIONES ESPAÑOLAS A RUSIA }\end{array}$} & \multirow[b]{2}{*}{$\begin{array}{c}\text { Ranking } \\
\text { España como } \\
\text { suministrador de } \\
\text { Rusia }\end{array}$} \\
\hline & $\begin{array}{l}\text { Exportaciones } \\
\text { españolas a } \\
\text { Rusia } \\
\text { (mill. euros) }\end{array}$ & $\begin{array}{c}\text { TVA } \\
\text { exportaciones } \\
\text { a Rusia }\end{array}$ & $\begin{array}{l}\text { Exportaciones } \\
\text { españolas } \\
\text { totales } \\
\text { (mill. euros) }\end{array}$ & $\begin{array}{c}\text { TVA } \\
\text { exportaciones } \\
\text { españolas }\end{array}$ & $\begin{array}{c}\text { Porcentaje } \\
\text { exportaciones } \\
\text { españolas con } \\
\text { destino Rusia }\end{array}$ & $\begin{array}{c}\text { Ranking } \\
\text { Rusia como } \\
\text { mercado } \\
\text { destino }\end{array}$ & $\begin{array}{c}\text { Cuota española } \\
\text { en total de } \\
\text { importaciones } \\
\text { rusas }\end{array}$ & \\
\hline $1993 \ldots \ldots . . .$. & 228 & nd & 46.606 & 16,5 & 0,2 & nd & 0,9 & 28 \\
\hline $1994 \ldots \ldots \ldots$ & 235 & 3,0 & 58.578 & 25,7 & 0,3 & nd & 1,0 & 32 \\
\hline $1995 \ldots \ldots \ldots$ & 309 & 31,4 & 69.962 & 19,4 & 0,4 & 33 & 0,9 & 30 \\
\hline $1996 \ldots \ldots \ldots$ & 451 & 45,8 & 78.212 & 11,8 & 0,6 & 25 & 1,0 & 24 \\
\hline $1997 \ldots \ldots . .$. & 729 & 61,7 & 93.419 & 19,4 & 0,8 & 19 & 1,1 & 23 \\
\hline $1998 \ldots \ldots \ldots$ & 618 & $-15,2$ & 99.849 & 6,9 & 0,6 & 22 & 1,3 & 22 \\
\hline $1999 \ldots \ldots . .$. & 394 & $-36,2$ & 104.789 & 4,9 & 0,4 & 33 & 1,2 & 22 \\
\hline $2000 \ldots \ldots \ldots$ & 578 & 46,6 & 124.177 & 18,5 & 0,5 & 30 & 1,1 & 20 \\
\hline $2001 \ldots \ldots \ldots$ & 744 & 28,8 & 129.771 & 4,5 & 0,6 & 23 & 1,2 & 21 \\
\hline $2002 \ldots \ldots . .$. & 795 & 6,8 & 133.268 & 2,7 & 0,6 & 23 & 1,4 & 21 \\
\hline $2003 \ldots \ldots \ldots$ & 819 & 3,0 & 138.119 & 3,6 & 0,6 & 23 & 1,2 & 20 \\
\hline $2004 \ldots \ldots . . .$. & 905 & 10,5 & 146.925 & 6,4 & 0,6 & 21 & 1,1 & 20 \\
\hline $2005 \ldots \ldots \ldots$ & 1.098 & 21,3 & 155.005 & 5,5 & 0,7 & 21 & 1,1 & 23 \\
\hline $2006 \ldots \ldots \ldots$ & 1.514 & 37,8 & 170.439 & 10,0 & 0,9 & 17 & 1,3 & 22 \\
\hline $2007 \ldots \ldots \ldots$ & 2.093 & 38,3 & 185.023 & 8,6 & 1,1 & 16 & 1,3 & 22 \\
\hline $2008 \ldots \ldots \ldots$ & 2.837 & 35,5 & 189.228 & 2,3 & 1,5 & 11 & 1,4 & 21 \\
\hline $2009 \ldots \ldots . .$. & 1.476 & $-48,0$ & 159.890 & $-15,5$ & 0,9 & 17 & 1,6 & 23 \\
\hline $2010 \ldots \ldots \ldots$ & 1.991 & 34,9 & 186.780 & 16,8 & 1,1 & 17 & 1,3 & 24 \\
\hline $2011 \ldots \ldots \ldots$ & 2.526 & 26,9 & 215.230 & 15,2 & 1,2 & 16 & 1,2 & 24 \\
\hline $2012 \ldots \ldots \ldots$ & 2.951 & 16,8 & 226.115 & 5,1 & 1,3 & 16 & 1,2 & 21 \\
\hline $2013 \ldots \ldots \ldots$ & 2.813 & $-4,7$ & 235.814 & 4,3 & 1,2 & 17 & 1,3 & 21 \\
\hline $2014^{\star} \ldots \ldots \ldots$ & 2.549 & $-9,4$ & 240.035 & 1,8 & 1,1 & 18 & nd & nd \\
\hline \multicolumn{9}{|c|}{$\begin{array}{l}\text { *Datos provisionales. } \\
\text { nd: no disponible. } \\
\text { TVA: tasa de variación anual. } \\
\text { Fuente: elaboración propia con datos de DataComex y OMC (cuota española en el total de las importaciones rusas y ranking de España como } \\
\text { suministrador de Rusia). }\end{array}$} \\
\hline
\end{tabular}

determinarse con exactitud (como en los años anteriores) las exportaciones totales a Rusia, algo que sólo se puede hacer a partir de 1993, cuando la URSS ya no aparece. De ese año hasta la actualidad, las exportaciones españolas a Rusia y su tasa de variación se recogen en el Cuadro 1 , junto con otros indicadores como las exportaciones totales y su tasa de variación, el porcentaje de exportaciones españolas con destino a Rusia, el ranking de Rusia como mercado de destino, la cuota española en importaciones rusas y el ranking de España como suministrador de Rusia.

Desde el punto de vista del marco legal de las relaciones comerciales, en un primer momento se rigieron por un acuerdo de 1990, de los llamados de «segunda generación», firmado por la entonces todavía Comunidad Europea con la URSS, un Acuerdo de Comercio y Cooperación Económica ${ }^{1}$ que le concedía la cláusula de Nación Más Favorecida y un calendario de reducción de las restricciones

1 http://trade.ec.europa.eu/doclib/docs/2008/july/tradoc_ 139580.pdf cuantitativas para 1995². Posteriormente, en 1994 se firmó el Acuerdo de Colaboración y Cooperación (ACC), que entró en vigor en 1997 y que ha regulado no sólo las relaciones económicas (uno de los principales objetivos de dicho acuerdo es la promoción del comercio y la inversión entre las partes) sino también las políticas. Un nuevo acuerdo se empezó a negociar en 2008, pero tras varias interrupciones, todavía no se ha llegado a concluir. El acuerdo en vigor permite que Rusia se beneficie del Sistema de Preferencias Generalizadas (SPG) comunitario que permite el acceso al mercado comunitario en condiciones preferenciales a los productos provenientes de países en vías de desarrollo (PVD).

Resulta de especial importancia el hecho de que, más de diecinueve años de haber solicitado su adhesión, el 22 de agosto de 2012 la Federación $\triangleright$

2 Antes de este acuerdo de 1990, la CEE no tenía ningún acuerdo formal con la URSS. Como este país, al contrario que otros países del Este, no fue nunca miembro del GATT, se le aplicaba el régimen de comercio menos preferencial de todos, el reservado a países con comercio de Estado. 
Rusa se convirtió en el $156^{\circ}$ miembro de la Organización Mundial del Comercio (OMC). Desde la incorporación de China en 2001, Rusia era la única gran economía del mundo que no formaba parte de la OMC. Como consecuencia de su adhesión, la Federación Rusa asumió el compromiso de adoptar la normativa de esta organización. Entre los aspectos más relevantes que ello implica, cabe destacar que el arancel máximo que el país podrá aplicar será, en promedio, de 7,8 por 100, frente al 10 por 100 vigente en 2011 . El arancel aplicado será igual al consolidado a partir de la adhesión para más de un tercio de los productos, en tanto que un cuarto de los recortes será efectivo al cabo de tres años. Los períodos de aplicación más largos corresponden a aves de corral (8 años) y vehículos de motor, helicópteros y aeronaves civiles (7 años). Algunos productos agropecuarios estarán sujetos a aranceles específicos (azúcar) y otros a contingentes arancelarios (carnes bovinas y porcinas, entre otros).

Sin embargo, tal y como señala la Unión Europea, Rusia no está respetando todos los compromisos adquiridos, aún antes de la imposición de las sanciones $^{3}$. De hecho, la prohibición de importación de carne de cerdo introducida en febrero de 2014 fue recurrida por la Comisión Europea ante el Órgano de Solución de Diferencias de la OMC ${ }^{4}$.

Entre 1994 y 2014, las exportaciones españolas se multiplican por 10, al pasar de los 235 millones de 1994 a los 2.549 de 2014. El máximo se alcanzó en 2012, con 2.951 millones de euros, y después cayó un 4,7 por 100 en 2013, hasta los 2.813 millones y otro 9,4 por 100 adicional en 2014.

En estos 21 años, las tasas de variación de las exportaciones españolas a Rusia han sido de dos dígitos excepto en 2002-2003 y en los dos últimos años. De estas 17 observaciones de dos dígitos, 14 han sido de signo positivo y tres de signo negativo. Estas tasas de variación son muy superiores a las tasas de variación de las exportaciones españolas totales, y como se puede observar en el Gráfico 1,

3 http://ec.europa.eu/trade/policy/countries-and-regions/countries/ russial

${ }^{4}$ http://trade.ec.europa.eu/doclib/press/index.cfm?id=1057 parecen más influidas por las oscilaciones del producto interior bruto ruso, que por la constante depreciación del rublo frente al euro, que no parece haber jugado un papel relevante.

A lo largo de este tiempo, las exportaciones españolas a Rusia han pasado de ser el 0,2 por 100 del total de nuestras exportaciones en 1993 a representar el 1,1 por 100 en 2014, aunque la cifra más alta fue el 1,5 por 100 alcanzado en 2008. En 2013, antes de las sanciones, llegaron a suponer el 1,2 por 100. Esto supone que Rusia ha pasado de ser nuestro $33^{\circ}$ cliente en 1995 al $18^{\circ}$ en 2014, llegando a ser el $11^{\circ}$ en 2008. Desde el punto de vista ruso, España fue en 2014 su $21^{\circ}$ proveedor ( $28^{\circ}$ en 1993 y el $32^{\circ}$ en 1994 , según los datos de la Organización Mundial de Comercio). El mejor puesto en este ranking ha sido el $20^{\circ}$, lo que sucedió en 2000, 2003 y 2004. La cuota española en el total de las importaciones rusas fue del 1,6 por 100 en 2009, pero hay que tener en cuenta que ese año fue atípico: nuestras exportaciones a Rusia cayeron un 48 por 100 pero la de otros suministradores cayeron todavía más.

Si comparamos la composición de nuestras exportaciones a Rusia en 1995 y en 2013 vemos la evolución que se ha producido. Todos los sectores han aumentado considerablemente sus exportaciones, especialmente el sector del automóvil y el de los productos químicos. El sector agroalimentario, a pesar de ser todavía el más relevante, ha perdido la mitad de su peso en estos 20 años.

\section{Las sanciones europeas y la respuesta rusa}

El 29 de julio de 2014 la Unión Europea acordó imponer a Rusia sanciones económicas que afectan a su industria petrolera y de defensa, productos de doble uso y tecnologías sensibles ${ }^{5}$, debido a las actividades rusas en la crisis de Crimea.

En concreto, las sanciones prohíben a los ciudadanos y empresas de la UE comprar o vender $\triangleright$

\footnotetext{
5 http://www.boe.es/doue/2014/229/L00001-00011.pdf
} 

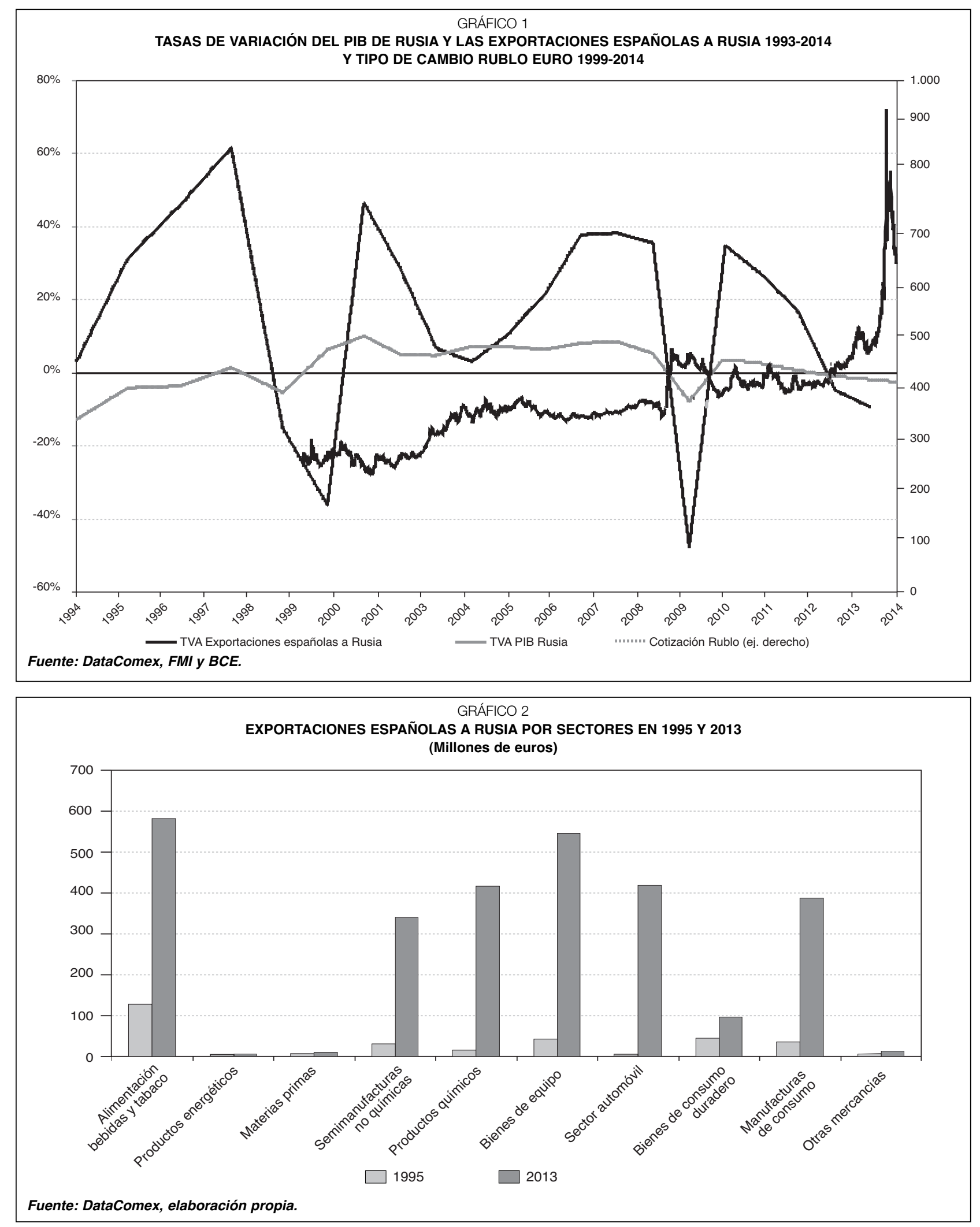

nuevos bonos, acciones o instrumentos financieros similares, con un vencimiento superior a 90 días, emitidos por los bancos estatales rusos.
Además, las sanciones limitan la exportación de equipos para la exploración de petróleo en aguas profundas, la exploración de la plataforma del $\triangleright$ 


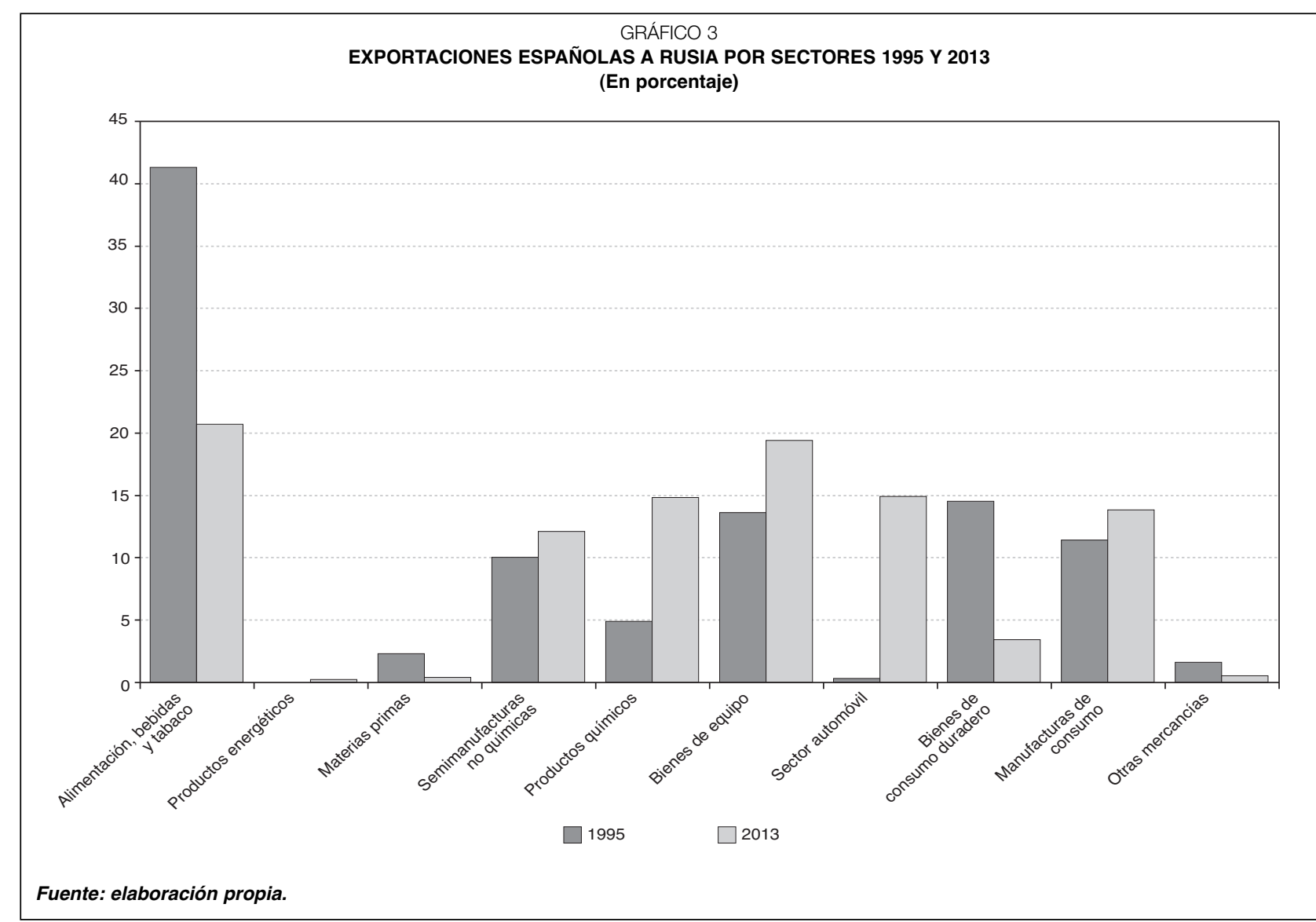

Ártico y la producción de petróleo, así como para proyectos relacionados con el petróleo de esquisto.

También se prohibieron nuevos contratos de venta de armas a Rusia y de exportación de maquinaria, de dispositivos electrónicos y de otros productos civiles de posible uso militar. Además, ese mismo martes 29 de julio, los embajadores ante la UE acordaron extender la lista de sanciones impuestas a Rusia a otros cuatro empresarios, hombres de negocios cercanos a los dirigentes rusos, a los que se prohibiría la entrada en los países de la UE y cuyos activos serían congelados, y a cuatro entidades jurídicas, entre ellas a un banco. Las sanciones fueron publicadas el 31 de julio y entraron en vigor el 1 de agosto. Posteriormente se ampliaron en septiembre y otra vez en febrero de 2015, cuando la UE aumentó su lista de sancionados hasta las 151 personas y 37 entidades actuales.

La respuesta rusa fue inmediata, ya que se produjo al día siguiente, adoptando la forma de un decreto «sobre la aplicación de determinadas medidas económicas especiales para garantizar la seguridad de la Federación de Rusia» que prohíbe, a partir de ese miércoles 6 de agosto de 2014, la entrada al territorio ruso de productos agrícolas, alimentos y materias primas originarios de los Estados que «han decidido imponer sanciones económicas contra las personas jurídicas y/o físicas rusas o se han unido a esta decisión». De este modo, Rusia cierra su mercado a los productos de EEUU, la UE, Noruega, Australia y Canadá. Está previsto que las medidas tengan una vigencia de un año.

Habría que señalar que uno de los productos afectados, la carne de porcino, ya tenía prohibida la entrada con anterioridad. En efecto, en febrero de 2014, Rusia cerró su mercado a las exportaciones europeas de cerdos, carne de porcino y algunos productos derivados, basándose en cuatro casos aislados de gripe porcina africana en jabalíes en las fronteras de Lituania y Polonia con Bielorrusia. Además, ya en 2013 se introdujeron fuertes restricciones, como veremos más adelante. 


\section{Evolución del comercio español desde las sanciones}

El veto entró en vigor el 6 de agosto (excepto para la carne de cerdo, que ya sufría una prohibición desde marzo), por lo que a la hora de hacer la comparación entre los años 2013 y 2014 hay que tener en cuenta que sólo afecta a 5 meses de ese último año.

En el Cuadro 2 vemos cómo el sector agroalimentario (el de mayor peso en 2013) cayó un 27,6 por 100 interanual, aunque la caída del total de sectores ha sido menor, $-9,4$ por 100 , gracias al comportamiento positivo de otras partidas, como la de bienes de equipo $(17,8$ por 100$)$ o la de productos químicos (12,8 por 100). Habría que destacar la fuerte disminución también del sector del automóvil, $-50,6$ por 100 , pero ello no se ha debido al veto, ya que esta partida no estaba afectada, sino más bien a cuestiones domésticas rusas (la caída de la producción rusa rozó el 60 por 100 en 2014, y marcas como Seat o General Motors han decidido recientemente abandonar el mercado ruso).

Sin embargo, para observar los efectos del veto hay que centrarse únicamente en las partidas afectadas por él y en el periodo desde su aplicación hasta los últimos datos disponibles, es decir desde agosto 2014 a febrero 2015, y compararlo con un periodo similar (periodo de control) en el pasado, es decir, de agosto 2013 a febrero de 2014, tal y como se hace en el Cuadro 3; el cual nos permite ver si la caída de exportaciones de estos productos a Rusia ha sido compensada con el aumento de las exportaciones a otros destinos (bajo el supuesto de que la producción se ha mantenido constante).

Por subsectores, el de carne ha aumentado sus exportaciones en 2,6 por 100 desde que se introdujo el veto hasta la actualidad en comparación con el mismo periodo agosto 2013-febrero 2014. En concreto, la partida de carne bovina ha aumentado sus exportaciones un 16,9 por 100 , destacando como nuevo destino Hong-Kong (ver
Anexo), que pasa de no importar prácticamente nada a hacerlo en una cuantía similar a la que se exportaba a Rusia.

Únicamente la partida de carne porcina muestra un ligero retroceso (17 millones de euros) respecto al periodo de control, eso sí, en una cuantía superior a la que se exportaba a Rusia (2,6 millones de euros), aunque hay que tener en cuenta que 2013 ya fue un año malo para las exportaciones de cerdo a Rusia, ya que apenas alcanzaron 1,1 millones de euros. La razón es que, a finales de marzo de 2013, Rusia introdujo unas restricciones en el sector de la carne tras una inspección a 19 establecimientos cárnicos, en la que aseguró haber encontrado motivos serios para dudar de la seguridad alimentaria y los controles veterinarios españoles. Las medidas supusieron una prohibición completa de importación de carne fresca y congelada, productos cárnicos y, más adelante, también pescado congelado y productos lácteos. A lo largo de 2013 se hicieron nuevas inspecciones tras las cuales Rusia fue autorizando algunos establecimientos, especialmente para embutidos, carne fresca y congelada. Posteriormente, en febrero de 2014, se volvió a limitar la importación de carne de cerdo por los casos de peste porcina ya comentados. Por ello, es mejor comparar un periodo anterior, el de agosto de 2012 a febrero de 2013, en el que se exportaron (ver Anexo) 81 millones de euros (frente a los 2,6 en el periodo agosto 2013-febrero 2014). Así, desde la introducción de las sanciones han aumentado las exportaciones un 7,7 por 100 , destacando el fuerte aumento de algunos mercados, como Japón, que pasa de 56 millones de euros a 131 millones de euros, Corea del Sur (de 17 a 90 millones de euros), China (de 43 a 80 millones de euros), Filipinas (de 3 a 12 millones), así como la introducción en nuevos mercados como Kirguizistán, Taiwán, Nueva Zelanda o Cuba.

Algo similar sucede con el subsector de pescado, que ha tenido un aumento del 4,6 por 100, aunque algunas de sus partidas (pescado vivo, congelado o en filetes) sí que han tenido una $D$ 
EFECTOS DEL VETO RUSO EN LAS EXPORTACIONES ESPAÑOLAS

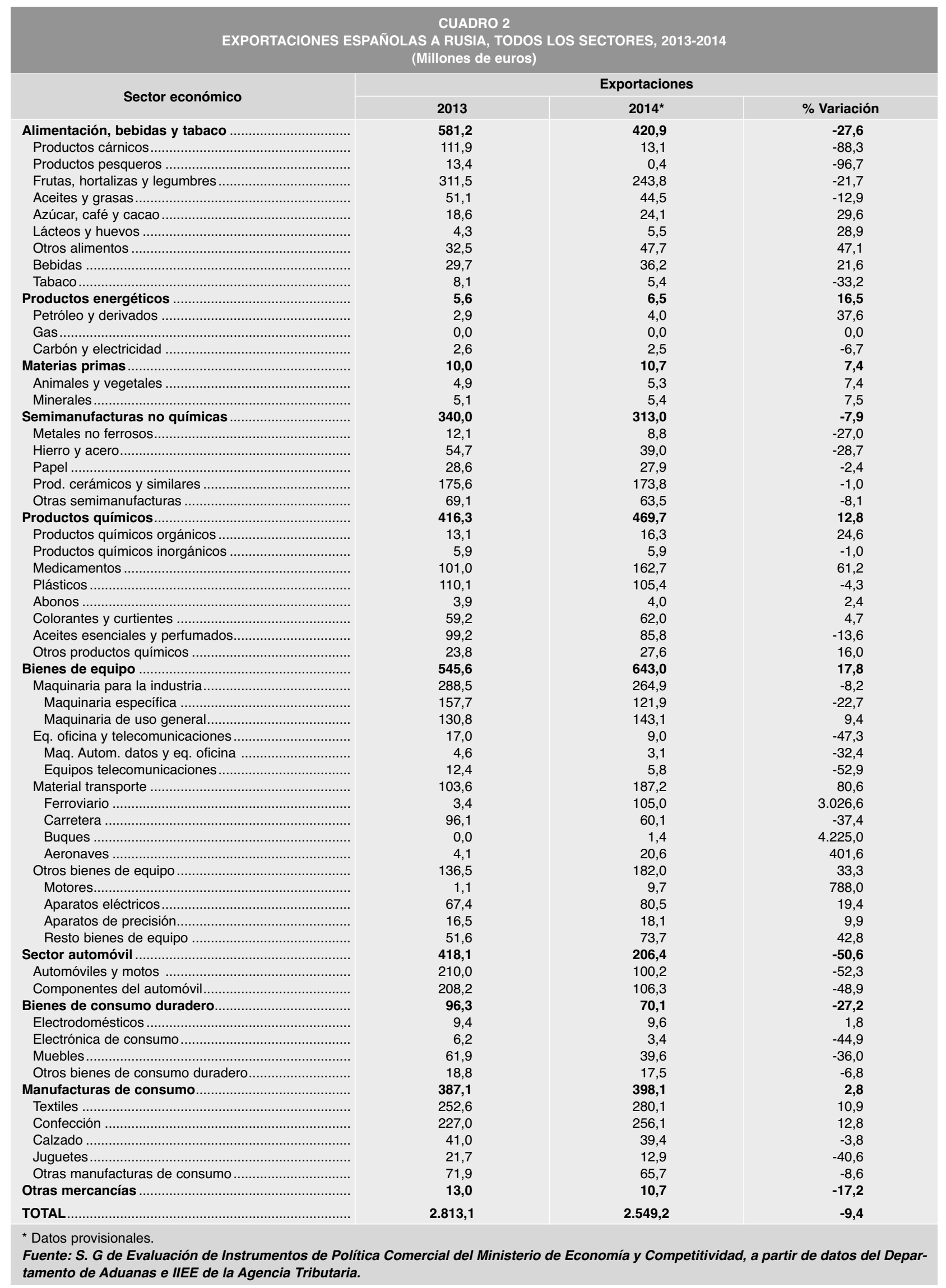




\begin{tabular}{|c|c|c|c|c|c|c|}
\hline \multicolumn{7}{|c|}{$\begin{array}{l}\text { CUADRO } 3 \\
\text { EXPORTACIONES ESPAÑOLAS AL MUNDO Y A RUSIA DE LOS PRODUCTOS VETADOS POR RUSIA } \\
\text { (En euros) }\end{array}$} \\
\hline & \multicolumn{6}{|c|}{ Exportaciones } \\
\hline & \multicolumn{3}{|c|}{ Mundo } & \multicolumn{3}{|c|}{ Rusia } \\
\hline & Ago 13-Feb 14 & Ago 14-Feb 15 & \% Variación & Ago 13-Feb 14 & Ago 14-Feb 15 & \% Variación \\
\hline Carne.... & 2.308.027.382 & 2.369.139.102 & 2,6 & 8.654 .055 & 393.126 & $-95,5$ \\
\hline 0201 Carne de animales de la especie bovina, fresca o refrigerada .............. & 219.137 .629 & 222.920 .386 & 1,7 & - & - & 0,0 \\
\hline 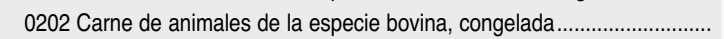 & 50.602 .403 & 59.169 .873 & 16,9 & 5.579 .641 & - & $-100,0$ \\
\hline 0203 Carne de animales de la especie porcina, fresca, refrig. o cong......... & 1.515 .069 .622 & 1.498.805.173 & $-1,1$ & 2.626 .374 & - & $-100,0$ \\
\hline 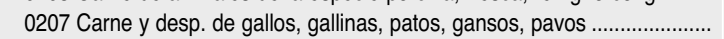 & 129.930 .405 & 182.917 .670 & 40,8 & - & - & 0,0 \\
\hline 0210 Carne y desp. comest, salados o ensalmuera, secos 0 ahumados.......... & 225.749 .583 & 233.421 .585 & 3,4 & 418.075 & 390.216 & $-6,7$ \\
\hline 160100 Embutidos y similares, de carne & 167.537 .739 & 171.904 .415 & 2,6 & 29.964 & 2.910 & $-90,3$ \\
\hline Pescado & 1.280.478.409 & 1.338.742.029 & 4,6 & 1.667 .948 & 0 & $-100,0$ \\
\hline 0301 Peces vivos & 28.396 .204 & 28.132 .825 & $-0,9$ & - & - & 0,0 \\
\hline 0302 Pescado fresco o refrigerado (excepto los de la partida 0304)............. & 217.614.576 & 248.492 .822 & 14,2 & - & - & 0,0 \\
\hline 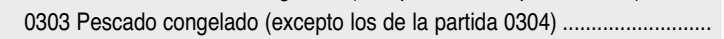 & 415.270 .285 & 400.646 .851 & $-3,5$ & 1.071 .094 & - & $-100,0$ \\
\hline 0304 Filetes y demás carne de pescado, frescos, refrigerados o congelados. & 141.254 .653 & 133.484 .531 & $-5,5$ & 108.532 & - & $-100,0$ \\
\hline 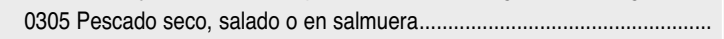 & 40.581 .221 & 45.106 .571 & 11,2 & - & - & 0,0 \\
\hline 0306 Crustáceos & 185.413 .609 & 187.140 .802 & 0,9 & - & - & 0,0 \\
\hline 0307 Moluscos & 250.647 .281 & 293.302 .520 & 17,0 & 488.323 & - & $-100,0$ \\
\hline 0308 Invertebrados acuáticos, excepto los crustáceos y moluscos............... & 1.300 .581 & 2.435 .107 & 87,2 & - & - & 0,0 \\
\hline Lácteos & 496.604 .056 & 514.327 .801 & 3,6 & 3.761 & 123.324 & $3.178,8$ \\
\hline 0401 Leche y nata (crema), sin concentrar & 124.811 .215 & 125.943 .564 & 0,9 & - & - & 0,0 \\
\hline 0402 Leche y nata (crema), concentradas ......... & 46.274 .589 & 45.644 .973 & $-1,4$ & - & - & 0,0 \\
\hline 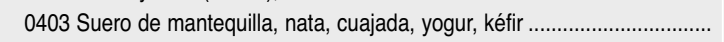 & 75.521 .690 & 82.792 .341 & 9,6 & - & 11 & 0,0 \\
\hline 0404 Lactosuero & 30.059 .007 & 24.684 .775 & $-17,9$ & - & - & 0,0 \\
\hline 0405 Mantequilla (manteca) y demás materias grasas de la leche ................ & 38.717 .976 & 30.595 .267 & $-21,0$ & - & - & 0,0 \\
\hline 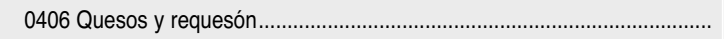 & 181.219 .579 & 204.666 .882 & 12,9 & 3.761 & 123.313 & $3.178,5$ \\
\hline Legumbre, hortaliza . & 2.949.316.271 & 2.936 .659 .916 & $-0,4$ & 54.160 .951 & 16.727 & $-100,0$ \\
\hline 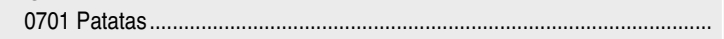 & 40.154 .743 & 19.110.204 & $-52,4$ & - & - & 0,0 \\
\hline 07020000 Tomates ............ & 621.908 .794 & 584.712 .800 & $-6,0$ & 27.459 .407 & - & $-100,0$ \\
\hline 0703 Cebollas, ajos, puerros & 165.904 .950 & 166.502 .034 & 0,4 & 28.711 & - & $-100,0$ \\
\hline 0704 Coles, coliflor y repollo & 201.992 .600 & 234.046 .875 & 15,9 & 1.000 .587 & - & $-100,0$ \\
\hline 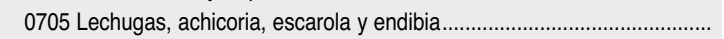 & 385.968 .731 & 382.997 .435 & $-0,8$ & 3.464 .046 & - & $-100,0$ \\
\hline 0706 Zanahorias, nabos, remolachas, rábano & 22.287 .543 & 21.004 .721 & $-5,8$ & - & - & 0,0 \\
\hline 070700 Pepinos y pepinillos & 381.855 .864 & 338.455 .371 & $-11,4$ & 12.153 .878 & - & $-100,0$ \\
\hline 0708 Hortalizas de vaina & 22.286 .720 & 23.962 .897 & 7,5 & 4.890 & - & $-100,0$ \\
\hline 0709 Las demás hortalizas: espárragos, berenjenas, apio, hongos ............. & 833.815 .339 & 873.583 .006 & 4,8 & 9.404 .997 & 16.710 & $-99,8$ \\
\hline 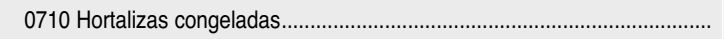 & 194.710 .967 & 215.697 .921 & 10,8 & 346.104 & 15 & $-100,0$ \\
\hline 0711 Hortalizas conservadas provisionalmente & 30.269 .475 & 30.678 .102 & 1,3 & 26.774 & 2 & $-100,0$ \\
\hline 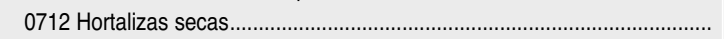 & 22.680 .623 & 18.701 .024 & $-17,5$ & 270.073 & - & $-100,0$ \\
\hline 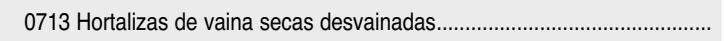 & 17.038 .540 & 13.681 .965 & $-19,7$ & 1.445 & - & $-100,0$ \\
\hline 0714 Raíces de mandioca, arrurruz, patacas, batatas, raíces ....................... & 8.441 .382 & 13.525 .560 & 60,2 & 39 & - & $-100,0$ \\
\hline 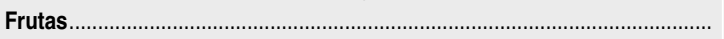 & 3.935 .511 .069 & 3.927.514.349 & $-0,2$ & 71.879 .815 & 2.465.295 & $-96,6$ \\
\hline 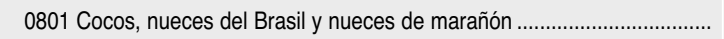 & 6.839 .976 & 6.602 .893 & $-3,5$ & - & - & 0,0 \\
\hline 0802 Los demás frutos de cáscara: almendras, avellanas, nueces............... & 321.850 .299 & 434.395 .689 & 35,0 & 1.936 .816 & 23 & $-100,0$ \\
\hline 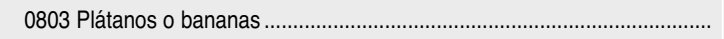 & 52.221 .420 & 55.228 .002 & 5,8 & 32 & - & $-100,0$ \\
\hline 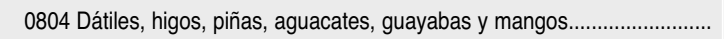 & 108.048 .871 & 161.414 .142 & 49,4 & 11.147 & - & $-100,0$ \\
\hline 0805 Cítricos & 1.920 .467 .244 & 2.049 .785 .826 & 6,7 & 22.989 .047 & 116.870 & $-99,5$ \\
\hline 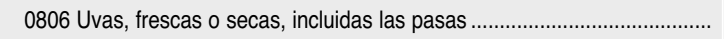 & 197.076 .698 & 188.040 .009 & $-4,6$ & 3.359 .874 & 34.930 & $-99,0$ \\
\hline 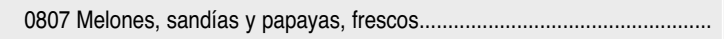 & 179.834 .912 & 128.997.092 & $-28,3$ & 99.489 & - & $-100,0$ \\
\hline 0808 Manzanas, peras y membrillos frescos & 129.459 .782 & 116.472 .088 & $-10,0$ & 5.875 .294 & 295.143 & $-95,0$ \\
\hline 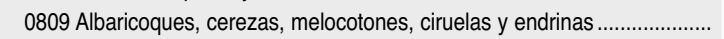 & 356.900 .790 & 293.561 .929 & $-17,7$ & 18.764 .120 & 2.013 .720 & $-89,3$ \\
\hline 0810 Las demás frutas: fresas, frambuesas, grosellas, kiwis, caquis........... & 583.232 .824 & 417.992 .540 & $-28,3$ & 18.550 .538 & - & $-100,0$ \\
\hline 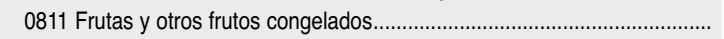 & 34.703 .461 & 35.949 .175 & 3,6 & - & - & 0,0 \\
\hline 0813 Frutas y otros frutos, secos & 44.874 .791 & 39.074 .964 & $-12,9$ & 293.459 & 4.609 & $-98,4$ \\
\hline Preparados & 258.054.170 & 260.513.666 & 1,0 & 749.585 & 772.615 & 3,1 \\
\hline 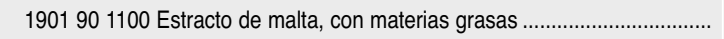 & 115.488 & 256.994 & 122,5 & - & - & 0,0 \\
\hline 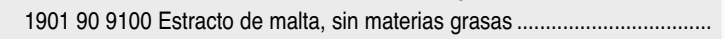 & 721.346 & 1.576 .074 & 118,5 & 7.650 & - & $-100,0$ \\
\hline 2106909200 Prepa alimen no expres ni compren sin materia grasa.......... & 42.271 .901 & 46.815 .581 & 10,7 & 125.066 & 995 & $-99,2$ \\
\hline 2106909800 Preparados alimen no expres en otra parte, las demás ........ & 214.945 .436 & 11.865 .017 & 1,4 & 616.869 & 771.619 & 25,1 \\
\hline TOTAL & 11.227.991.357 & 11.346 .896 .863 & 1,1 & 137.116.115 & 3.771 .086 & $-97,2$ \\
\hline & & & & & & \\
\hline
\end{tabular}


evolución negativa. La más relevante, desde el punto de vista de las exportaciones a Rusia, era la del pescado congelado, con 1 millón de euros de exportaciones en el periodo de control. En el periodo posterior a las sanciones rusas observamos cómo en otros mercados la pérdida ha sido mayor, ya que se han dejado de exportar $4,5 \mathrm{mi}-$ llones de euros a Portugal, se han exportado casi 2 millones de euros menos a Italia o casi 12 millones de euros menos a Mauricio, mientras que han aumentado las exportaciones a otros destinos en cantidades también mayores (por ejemplo, 15 millones más que el año anterior a Costa de Marfil, ver Anexo).

Las exportaciones del subsector de lácteos también han experimentado una subida del 3,6 por 100 desde el comienzo del veto hasta la actualidad y lo que es más, la única partida que se exportaba a Rusia, la 0406 quesos y requesón, ha aumentado sus exportaciones en un 12,9 por 100, aumentando incluso las exportaciones a Rusia (esto es debido a que la exportación de algunas subpartidas está permitida).

El subsector de legumbres y hortalizas sí que ha tenido un ligero retroceso del 0,4 por 100 en sus exportaciones totales desde la fecha del veto hasta la actualidad, aunque el resultado es muy variable dependiendo de la partida. Así, dos partidas que han evolucionado negativamente en sus exportaciones totales, la 0701 patatas frescas (-52 por 100) o la 0706 zanahorias, nabos, remolachas $(-5,8$ por 100), no exportaban nada a Rusia anteriormente. Otras dos, la 0712 hortalizas secas (-17,5 por 100) y la 0713 hortalizas de vaina $(-19,75$ por 100$)$ exportaban a Rusia cantidades marginales, con lo que el veto no explicaría esta caída en las exportaciones españolas totales.

Existirían tres partidas con cantidades relevantes y que han experimentado caídas. Se trata en primer lugar de la 0702 tomates, cuyas exportaciones han caído un 6 por 100. Se trata de una partida que en el periodo de control (agosto 2013-febrero 2014) tuvo unas exportaciones totales de 621 millones de euros, de las cuales 27 millones tuvieron Rusia como destino. La caída en el periodo post-veto es de 37 millones de euros, es decir, que la caída en las exportaciones del subsector no se explican únicamente por el veto ruso, aunque sí en gran medida. Curiosamente caen en idéntica cuantía las exportaciones de tomates a los Países Bajos (ver Anexo). La segunda sería la 0707 pepinos y pepinillos, que cae un 11,4 por 100 o, en términos absolutos, 43 millones de euros en comparación al periodo de control. A Rusia se exportaron 12 millones, con lo que la caída apenas puede atribuírsele en un 28 por 100 , cantidad muy similar a la disminución observada en las exportaciones a Alemania. En la tercera partida, la 0705 lechugas, la cantidad que se exportó a Rusia (3,4 millones de euros) es prácticamente idéntica a la caída de las exportaciones del sector en el periodo siguiente (2,9 millones de euros).

El comportamiento del sector de frutas muestra también un ligero retroceso, del 0,2 por 100, en sus exportaciones entre los dos periodos (aunque al tener un alto componente estacional, hay que analizar los meses venideros para tener una imagen completa de un ciclo de doce meses, lo que se haremos posteriormente). Sin embargo, la partida más importante, cítricos, que representa aproximadamente el 50 por 100 del total de exportaciones del subsector en ambos periodos y que era la segunda partida más importante en las exportaciones a Rusia, únicamente después del tomate, ha experimentado un avance del 6,7 por 100. En efecto, los casi 23 millones que se han dejado de exportar de cítricos a Rusia en el periodo agosto 2014- febrero 2015 respecto a agosto 2013-febrero 2014 se han visto más que compensados con un aumento de las exportaciones a Alemania y a Francia (100 millones más entre los dos países).

Otras dos partidas, la 0809 albaricoques y la 0810 demás frutas, exportaron a Rusia en el periodo anterior 18 millones de euros cada uno y para ellos el mercado ruso era un destino relevante, ya que representaba respectivamente el 5,26 y el 3,18 por 100 del total de sus exportaciones. Estas dos partidas han disminuido sus exportaciones totales en 63 millones y en 165 millones respectivamente, lo que significa que otros factores (caída de $\triangleright$ 


\begin{tabular}{|c|c|c|c|c|c|c|c|c|c|c|c|c|}
\hline \multicolumn{13}{|c|}{$\begin{array}{c}\text { CUADRO } 4 \\
\text { EXPORTACIONES MENSUALES DE PRODUCTOS AFECTADOS POR L } \\
\text { EN EL PERIODO JULIO 2013-AGOSTO } 2014 \\
\text { (Miles de euros) }\end{array}$} \\
\hline & \multicolumn{5}{|c|}{2013} & \multicolumn{7}{|c|}{2014} \\
\hline & $\mathrm{Ag}$ & Sp & Oc & $\mathrm{Nv}$ & Dc & En & $\mathrm{Fb}$ & $\mathrm{Mz}$ & $A b$ & My & $\mathrm{Jn}$ & ال \\
\hline Exportaciones totales & 196.578 & 239.500 & 266.848 & 221.988 & 167.123 & 213.721 & 203.756 & 241.640 & 216.168 & 256.693 & 208.553 & 251.119 \\
\hline 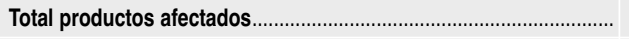 & 16.218 & 10.231 & 16.320 & 22.828 & 27.018 & 21.665 & 22.810 & 18.831 & 18.204 & 25.012 & 24.421 & 25.991 \\
\hline 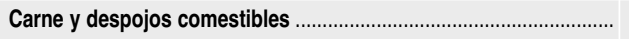 & 1.610 & 1.642 & 1.804 & 2.000 & 816 & 498 & 357 & 873 & 1.674 & 615 & 1.239 & 862 \\
\hline 0202 Carne de animales de la especie bovina, congelada ................ & 849 & 538 & 1.464 & 1.782 & 692 & - & 327 & 575 & 1.318 & 511 & 689 & 814 \\
\hline 0203 Carne de anim de la especie porc, fresca, refrig o conge ........ & 756 & 1.104 & 330 & 212 & 44 & 181 & - & - & - & - & - & - \\
\hline 0210 Carne y desp come, sal o en sal, sec 0 ahum; harina y polvo .... & 2 & - & - & - & 78 & 308 & 31 & 298 & 355 & 105 & 550 & 48 \\
\hline 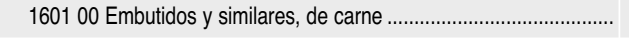 & 3 & & 9 & 6 & 2 & 9 & - & - & - & - & - & - \\
\hline Pescados, crustáceos y moluscos & - & 70 & 1.204 & 286 & - & 26 & 83 & 179 & - & - & - & - \\
\hline 0303 Pescado congelado (excepto los de la partida 0304) ............... & - & - & 1.071 & - & - & - & - & - & - & - & - & - \\
\hline 0304 File y demás carne de pesc frescos, refrig o congelados.......... & - & & 48 & 52 & - & - & - & - & - & - & - & 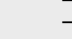 \\
\hline 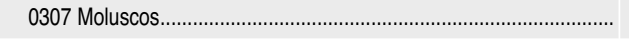 & - & 62 & 84 & 234 & - & 26 & 83 & 179 & - & - & - & - \\
\hline Leche, productos lácteos & 1 & - & 1 & - & - & 2 & - & - & 47 & 79 & 61 & 63 \\
\hline 0403 Suero de mantequilla, nata, cuajada, yogur, kéfir ......................... & - & - & - & - & - & - & - & - & - & - & 41 & - \\
\hline 0406 Quesos y requesón & 1 & - & 1 & - & - & 2 & - & - & 47 & 79 & 20 & 63 \\
\hline 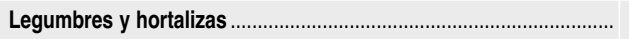 & 80 & 603 & 7.190 & 9.872 & 12.362 & 11.340 & 12.627 & 10.078 & 6.648 & 3.093 & 2.017 & 553 \\
\hline 07020000 Tomates & 78 & 191 & 2.482 & 4.723 & 6.547 & 7.028 & 6.373 & 5.662 & 4.099 & 1.740 & 1.349 & 259 \\
\hline 0703 Cebollas, ajos, puerros & - & - & - & - & - & 14 & 15 & - & - & - & - & 11 \\
\hline 0704 Coles, coliflor y repollo & - & - & 10 & 41 & 56 & 358 & 536 & 325 & 162 & 79 & 13 & - \\
\hline 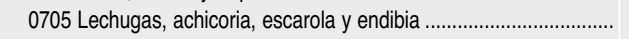 & 1 & 2 & 239 & 709 & 757 & 1.045 & 711 & 802 & 721 & 289 & 16 & - \\
\hline 0706 Zanahorias, nabos, remolachas, rábano & - & - & - & - & - & - & - & - & 6 & 7 & - & - \\
\hline 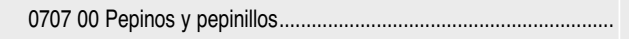 & - & 139 & 2.469 & 1.675 & 3.679 & 1.829 & 2.341 & 538 & 41 & 42 & 43 & 14 \\
\hline 0708 Hortalizas de vaina & - & - & - & - & 2 & 3 & - & - & 3 & - & - & - \\
\hline 0709 Las demás hort: espárragos, berenjenas, apio, hongos ............ & 1 & 214 & 1.881 & 2.628 & 1.300 & 941 & 2.412 & 2.436 & 1.363 & 798 & 428 & 77 \\
\hline 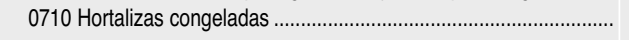 & - & - & - & 32 & 20 & 59 & 235 & 262 & 202 & 132 & 113 & 139 \\
\hline 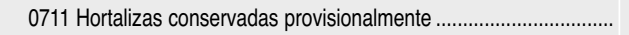 & - & - & 27 & - & - & - & - & - & - & - & - & - \\
\hline 0712 Hortalizas secas & - & 57 & 81 & 65 & 2 & 63 & 2 & 53 & 51 & - & 53 & 53 \\
\hline 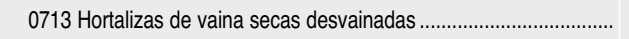 & - & - & - & - & - & - & 1 & - & - & 6 & - & - \\
\hline 0714 Raíces de man, arrurruz, pat, bata, raíces y tubér similares .... & - & - & - & - & - & - & - & - & - & - & 1 & - \\
\hline Frutas & 14.300 & 7.877 & 6.102 & 10.666 & 13.588 & 9.606 & 9.728 & 7.452 & 9.658 & 21.201 & 21.054 & 24.290 \\
\hline 0802 Los demás frutos de cás: almen, avella, nueces, castañas...... & 466 & 247 & 155 & 151 & 161 & 596 & 161 & 425 & 20 & 212 & 64 & 138 \\
\hline 0804 Dátiles, higos, piñas, aguacates, guayabas y mangos .............. & - & - & 6 & 1 & - & - & 4 & 15 & 16 & 22 & 26 & - \\
\hline 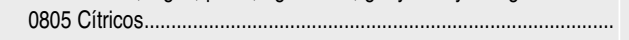 & - & 306 & 1.432 & 4.778 & 4.863 & 4.661 & 6.937 & 5.725 & 7.539 & 7.372 & 907 & 182 \\
\hline 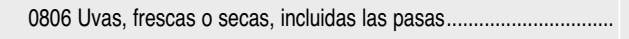 & 43 & 51 & 233 & 760 & 1.829 & 444 & - & - & - & - & - & 99 \\
\hline 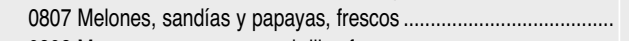 & - & 1 & 2 & 3 & 32 & 24 & 37 & 18 & 12 & 205 & 226 & 5 \\
\hline 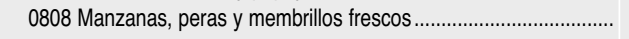 & 990 & 1.846 & 1.902 & 711 & 223 & 80 & 124 & 73 & 46 & & 28 & 842 \\
\hline 0809 Albaricoques, cerezas, melocotones, ciruelas y endrinas.......... & 12.801 & 5.036 & 860 & 34 & 34 & - & - & 1 & 663 & 12.105 & 19.689 & 23.025 \\
\hline 0810 Las demás frutas: fresas, frambuesas, grosellas, kiwis, caquis.... & - & 315 & 1.512 & 4.108 & 6.348 & 3.802 & 2.465 & 1.155 & 1.360 & 1.282 & 114 & - \\
\hline 0813 Frutas y otros frutos, secos & - & 75 & - & 120 & 99 & 0 & - & 41 & 3 & 2 & - & - \\
\hline Preparados alimenticios & 226 & 39 & 20 & 4 & 252 & 194 & 16 & 248 & 177 & 24 & 50 & 223 \\
\hline 1901909100 Estracto de malta, sin materias grasas .......................... & - & - & - & 3 & - & - & 4 & - & - & - & - & 3 \\
\hline 2106909200 Prepa alimenticios no expre ni compren sin mat gras... & 48 & - & 5 & - & - & 62 & 10 & 12 & 29 & - & - & 24 \\
\hline 2106909800 Prep alimenticios no expre en otra parte, las demás & 178 & 39 & 15 & - & 252 & 132 & 1 & 237 & 149 & 24 & 50 & 195 \\
\hline
\end{tabular}

producción o de pérdida de otros mercados, aumento de la demanda interna...) podrían haber jugado un papel importante. Así, por ejemplo (ver Anexo), también han caído las exportaciones de albaricoques a Alemania (en 23 millones de euros) o a Francia (en 10 millones de euros) y a Países Bajos y Portugal (8 millones de euros a cada uno), y las de la subcategoría 0810 las demás frutas, fresas... a Alemania (en 56 millones de euros), Francia (en 21 millones de euros) e Italia (en 25 millones de euros).
Lo mismo sucede, pero en menor cuantía, con las partidas 0808 manzanas, peras y membrillos (exportaciones de 5,8 millones de euros a Rusia de agosto 2013 a febrero 2014) y la 0806 uvas (3,3 millones de euros en ese mismo periodo), la caída de sus exportaciones totales en la comparación de los dos periodos es aproximadamente cuatro veces mayor que la cantidad que exportaban a Rusia en el primer periodo.

Respecto al último de los subsectores del sector agroalimentario, el de preparados alimenticios, ha $\triangleright$ 
aumentado sus exportaciones totales en un 1 por 100. Lo que es más, debido a que alguna de sus partidas no está incluida en el veto, incluso han aumentado las ventas de este capítulo a Rusia. Las dos únicas líneas perjudicadas en este capítulo exportaban unas cantidades modestas y además se han visto compensadas con fuertes aumentos en las exportaciones totales a otros destinos.

Como se ha dicho, el sector agroalimentario, o al menos determinados subsectores, tiene un marcado carácter estacional, por lo que resulta especialmente interesante estudiar si en los próximos cinco meses (de marzo a julio), es decir, hasta que se haya completado el ciclo entero de un año desde las sanciones, hay productos que puedan verse especialmente afectados. Por ello, en el Cuadro 4 se recogen las exportaciones mensuales de productos afectados por las sanciones rusas en el periodo julio 2013-agosto 2014 en el que se puede ver la estacionalidad de los mismos.

Observamos cómo el año pasado, tres de los sectores (pescados, lácteos y preparados) no exportaron cantidades significativas. Respecto a los otros tres, el primero de ellos es el de carne. Las cantidades de exportación de las distintas partidas son similares a las del periodo agosto-febrero, con lo que podemos concluir que el comportamiento será similar, es decir, el sector en su conjunto aumentará ligeramente sus exportaciones totales a pesar del embargo ruso. Habría que recordar que el sector porcino no exportó nada en esos meses de 2014 debido a la prohibición previa, de febrero de 2014 comenta$\mathrm{da}$, alegando algunos casos de peste porcina, y que ya 2013 había sido un año muy negativo comparado con los dos años anteriores.

Por lo que se refiere al sector de legumbres y hortalizas, en los meses de marzo a julio, el promedio mensual de exportaciones es ligeramente inferior al promedio de agosto-febrero, con lo que es razonable suponer que los efectos serán similares a los ya comentados.

En el sector de las frutas, por el contrario, las exportaciones mensuales promedio del periodo marzo-julio son sensiblemente superiores a las del periodo agosto-marzo (16,7 millones vs 10,26 millones de euros) fundamentalmente debido a que en mayo, junio y julio son muy importantes para las exportaciones de 0809 albaricoques (de hecho en junio y julio suponen casi el 95 por 100 de las exportaciones del capítulo). Al analizar el periodo desde el veto hasta la actualidad hemos visto cómo la caída de las exportaciones ha sido mayor que la que hubiera podido ser explicada por el veto ruso. Es previsible que esta partida, en vista de que mayo, junio y julio son sus mejores meses, tenga problemas y sea la más perjudicada por el veto. El comportamiento de otros mercados con más peso que Rusia, como Alemania, será determinante para establecer el balance definitivo.

En conclusión, vemos cómo algunos de los subsectores afectados por el veto han sido capaces de exportar más en el periodo agosto 2014febrero 2015 que en el de agosto 2013-febrero 2014. Entre estos merece especial mención por su importancia cuantitativa la partida de cítricos, que ha aumentado un 6,7 por 100 entre periodos, o la de carne bovina (16,9 por 100); la partida 0709 demás hortalizas: espárragos, apio, berenjenas... (4,8 por 100) y la 0802 los demás frutos de cáscara: almendras, avellanas, nueces, castañas, pistachos, piñones (35 por 100). Luego hay otras en los que las caídas experimentadas son mucho mayores que las que podrían ser explicadas por las sanciones rusas, con lo que es posible que haya otras causas. La partida más afectada es la del albaricoque, y dado que los meses más fuertes son junio y julio, queda por ver si se podrá encontrar mercados alternativos. En cuanto al porcino, comparado con el periodo agosto 2012 a febrero de 2013 , la situación ha mejorado, se han encontrado nuevos mercados (Kirguizistán, Taiwán, Nueva Zelanda o Cuba) o ampliado fuertemente otros (Japón, Corea del Sur y China).

Habría que matizar que hemos examinado los subsectores desde el punto de vista de comercio exterior, pero cabe la posibilidad de que se hayan producido otras pérdidas debido a caídas de los precios domésticos, puesto que esos productos $\triangle$ 
han sido en parte comercializados en la propia UE. Algunas asociaciones de agricultores y cooperativas europeas calculan que el precio de algunos productos ha podido caer hasta un 50 por 100 (alrededor de un 90 por 100 de las frutas, carne de cerdo y pollo se consumen en Europa).

Otra cuestión que queda por resolver es ver si Rusia ha encontrado suministradores alternativos, ya que compraba el 30 por 100 de frutas y más del 20 por 100 de sus hortalizas a los países de la Unión Europea. De momento no hay datos para poder saber si estos productos europeos han sido sustituidos y qué países, en su caso, se han convertido en nuevos suministradores de Rusia.

\section{Perspectiva comparada: impacto de las medidas en otros países de la UE}

Según un estudio del Parlamento Europeo ${ }^{6}$, con datos de 2013, la Unión Europea es la principal afectada por las sanciones, ya que el 73 por 100 de las importaciones prohibidas tienen origen en la misma. Es la principal perjudicada en todas las partidas excepto en la de pescado, en el la que Noruega sale más dañada. Aun así, según estimaciones de la UE, el impacto en el PIB será muy reducido, ya que la agricultura sólo supone el 1,7 por 100 del mismo.

Por sectores, los más perjudicados en términos absolutos son los lácteos (1.350 millones de euros en exportaciones a Rusia en 2013), las frutas y las carnes (ambos con 1.260 millones de exportaciones). Como proporción de las exportaciones serían el sector de frutas y hortalizas (el 29 por 100 de las exportaciones iban a Rusia), quesos (33 por 100, aunque apenas afecta a España) y la mantequilla (28 por 100).

La Comisión Europea hizo también una estimación de impacto que básicamente consistía en calcular las exportaciones en 2013 de los países miembros a Rusia de los productos en los que

6 The Russian Embargo: Impact on the Economic and Employment Situation in the EU Author: Susanne Kraatz, Policy Department A: Economy and Scientific Policy, European Parliament PE 536.291. recaería el veto. Según datos de la Comisión Europea, el valor de las exportaciones europeas al mercado ruso en 2013, correspondiente a los productos agrícolas y alimentarios vetados por Rusia, alcanza los 5.252 millones de euros.

Así, el país de la UE más afectado por las sanciones sería Lituania, que perdería unos 927 millones de euros, fundamentalmente por las exportaciones de requesón, carne, pienso, bebidas, patatas, judías enlatadas, pescado y cerdo. Después vendría Polonia, para quien Rusia es uno de sus mayores compradores de fruta y verdura. El sector agrícola polaco depende en buena medida de la producción de manzana. Las pérdidas de Polonia se podrían elevar a 841 millones de euros.

Alemania, principal socio europeo de Rusia, perdería aproximadamente 595 millones de euros. Además de exportar tecnología, maquinaria, vehículos y bienes de consumo, Rusia importa de esa nación carne y productos lácteos.

En cuarto lugar estaría Países Bajos, de donde Rusia importa productos lácteos, huevos, cereales y animales vivos por valor de unos $528 \mathrm{mi}-$ llones de euros. Después vendría Dinamarca, que exporta a Rusia unos 377 millones de euros, básicamente productos lácteos, huevos, miel, carne, pescado y marisco.

En sexto lugar figura España, cuyas pérdidas podrían alcanzar los 338 millones de euros, y cuyos componentes ya hemos analizado. Los principales productos importados de España por Rusia son: fruta, carne congelada, aceitunas y aceite de oliva (este último producto no está incluido en las sanciones).

Si analizamos las posibles pérdidas desde otros puntos de vista (Cuadro 5), observamos cómo Lituania resulta siempre perjudicada con cualquier criterio que tengamos en cuenta. Así, sus exportaciones a Rusia suponen el 4,1 por $100 \mathrm{del}$ total de las exportaciones de la UE en euros, que ascienden a 119.458 millones de euros, pero el 17,7 por 100 de los productos vetados, también en valor, del total de la UE (5.238 millones de euros). En otras palabras, el peso del veto en $D$ 


\begin{tabular}{|c|c|c|c|c|c|c|c|}
\hline \multicolumn{8}{|c|}{$\begin{array}{l}\text { CUADRO } 5 \\
\text { EXPORTACIONES DE LOS PAÍSES DE LA UE A RUSIA, EXPORTACIONES DE LOS PRODUCTOS VETADOS EN } 2013 \\
\text { (Millones de euros) }\end{array}$} \\
\hline Países & $\begin{array}{c}\text { Exportaciones } \\
\text { a Rusia }\end{array}$ & $\begin{array}{l}\text { Porcentaje } \\
\text { del total } \\
\text { UE }\end{array}$ & $\begin{array}{l}\text { Exportaciones } \\
\text { de productos } \\
\text { vetados }\end{array}$ & $\begin{array}{c}\text { Porcentaje } \\
\text { exportaciones } \\
\text { de productos } \\
\text { vetados sobre } \\
\text { el total de } \\
\text { productos } \\
\text { vetados UE }\end{array}$ & $\begin{array}{c}\text { Porcentaje } \\
\text { exportaciones } \\
\text { de productos } \\
\text { vetados sobre } \\
\text { el total de } \\
\text { exportaciones } \\
\text { a Rusia }\end{array}$ & $\begin{array}{c}\text { Porcentaje } \\
\text { exportaciones } \\
\text { de productos } \\
\text { vetados sobre } \\
\text { exportaciones } \\
\text { totales del país }\end{array}$ & $\begin{array}{l}\text { Porcentaje } \\
\text { exportaciones } \\
\text { totales }\end{array}$ \\
\hline Total UE 28 & 119.458 & 100,0 & 5.238 & 100,0 & - & - & 4.649 .032 \\
\hline 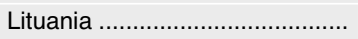 & 4.869 & 4,1 & 927,2 & 17,7 & 19,0 & 3,8 & 24.545 \\
\hline 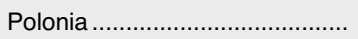 & 8.113 & 6,8 & 839,7 & 16,0 & 10,4 & 0,5 & 154.344 \\
\hline Alemania & 35.789 & 30,0 & 583,3 & 11,1 & 1,6 & 0,1 & 1.105 .683 \\
\hline 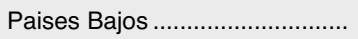 & 7.956 & 6,7 & 528,4 & 10,1 & 6,6 & 0,1 & 539.901 \\
\hline 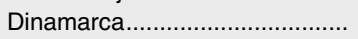 & 1.562 & 1,3 & 377,0 & 7,2 & 24,1 & 0,4 & 83.947 \\
\hline 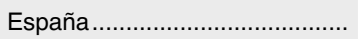 & 2.813 & 2,4 & 338,4 & 6,5 & 12,0 & 0,1 & 239.314 \\
\hline 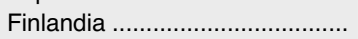 & 5.359 & 4,5 & 283,4 & 5,4 & 5,3 & 0,5 & 59.924 \\
\hline 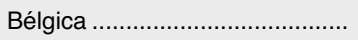 & 5.114 & 4,3 & 281,2 & 5,4 & 5,5 & 0,1 & 353.238 \\
\hline 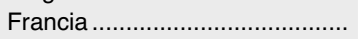 & 7.721 & 6,5 & 244,2 & 4,7 & 3,2 & 0,1 & 442.209 \\
\hline 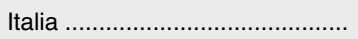 & 10.772 & 9,0 & 162,4 & 3,1 & 1,5 & 0,0 & 393.158 \\
\hline 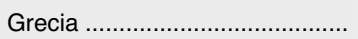 & 406 & 0,3 & 124,6 & 2,4 & 30,7 & 0,5 & 27.559 \\
\hline 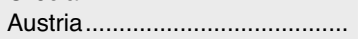 & 4.308 & 3,6 & 103,5 & 2,0 & 2,4 & 0,1 & 135.004 \\
\hline Irlanda & 633 & 0,5 & 90,3 & 1,7 & 14,3 & 0,1 & 86.177 \\
\hline 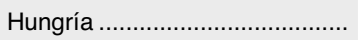 & 2.526 & 2,1 & 78,1 & 1,5 & 3,1 & 0,1 & 81.299 \\
\hline 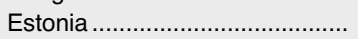 & 1.419 & 1,2 & 74,8 & 1,4 & 5,3 & 0,6 & 12.311 \\
\hline 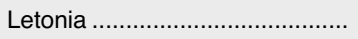 & 1.760 & 1,5 & 70,4 & 1,3 & 4,0 & 0,6 & 10.893 \\
\hline 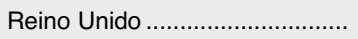 & 4.667 & 3,9 & 39,9 & 0,8 & 0,9 & 0,0 & 409.549 \\
\hline 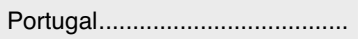 & 263 & 0,2 & 14,7 & 0,3 & 5,6 & 0,0 & 47.267 \\
\hline 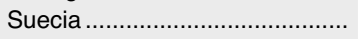 & 2.728 & 2,3 & 13,3 & 0,3 & 0,5 & 0,0 & 129.560 \\
\hline 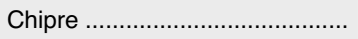 & 24 & 0,0 & 13,0 & 0,2 & 53,9 & 0,9 & 1.520 \\
\hline 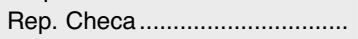 & 4.474 & 3,7 & 11,5 & 0,2 & 0,3 & 0,0 & 122.990 \\
\hline 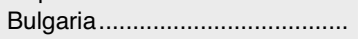 & 583 & 0,5 & 10,1 & 0,2 & 1,7 & 0,0 & 22.272 \\
\hline 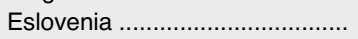 & 1.190 & 1,0 & 9,9 & 0,2 & 0,8 & 0,0 & 25.660 \\
\hline 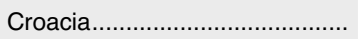 & 282 & 0,2 & 6,7 & 0,1 & 2,4 & 0,1 & 9.531 \\
\hline 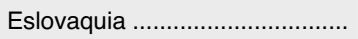 & 2.555 & 2,1 & 6,2 & 0,1 & 0,2 & 0,0 & 64.566 \\
\hline 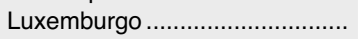 & 156 & 0,1 & 4,5 & 0,1 & 2,9 & 0,0 & 14.058 \\
\hline 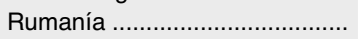 & 1.382 & 1,2 & 1,3 & 0,0 & 0,1 & 0,0 & 49.817 \\
\hline Malta & 36 & 0,0 & 0,0 & 0,0 & 0,0 & 0,0 & 2.738 \\
\hline
\end{tabular}

sus productos es muy superior al de la participación en las exportaciones europeas a Rusia. Este desequilibrio se da también en Polonia, cuyas exportaciones suponen el 6,8 por 100 del total de exportaciones de la UE pero sus productos son el 16 por 100 de los vetados, y en otros países como España, cuyas exportaciones representan el 2,4 por 100 de las exportaciones totales de la UE a Rusia y el 6,5 por 100 de los productos vetados, es decir, su cuota en los productos vetados es casi tres veces más grande que su cuota en las exportaciones de la UE a Rusia. Ello se explica por recaer las sanciones en el sector agroalimentario, que tiene mayor peso en las exportaciones españolas a Rusia que la media de los países.

Por el lado contrario, destacar que Alemania, cuyas exportaciones representan el 30 por 100 del total de las exportaciones de la UE a Rusia, tiene un porcentaje de productos afectados muy inferior a su participación en las exportaciones, un 11,1 por 100 . En mucha menor medida, lo mismo sucede con Francia (6,5 y 4,7 por 100 respectivamente).

Si nos fijamos en qué proporción cada país ve afectado su comercio con Rusia, dividiendo el valor de los productos afectados en 2013 de cada uno de ellos entre sus exportaciones a Rusia, vemos que el más perjudicado sería Chipre, ya que el 53 por 100 de sus exportaciones a Rusia se ven afectadas, aunque su cuantía en términos absolutos es pequeña. Le seguiría Grecia (30,7 por 100 de sus productos afectados), Dinamarca (24,1 por 100$)$, Lituania (19 por 100), Irlanda (14,3 por 100) y en sexto lugar, España, con un 12 por 100 de sus exportaciones afectadas por el veto. Siguiendo este $\triangleright$ 
criterio, los menos afectados serían Malta (con cifras insignificantes), Rumanía (las sanciones afectan únicamente al 0,1 por 100 de sus exportaciones, y estas son considerables, 1.382 millones, la mitad de las españolas), República Checa, (con 4.474 millones de euros de los cuales sólo se verían afectados el 0,3 por 100), Reino Unido (sólo el 0,9 por 100 de sus exportaciones de 2013 sufrirían el veto) y Alemania (1,6 por 100 de sus exportaciones están afectadas).

Si utilizamos como criterio el peso que los productos vetados tienen en las exportaciones totales de cada país de la UE, vemos que, excepto para Lituania, para la que los productos vetados suponen un 3,7 por 100 de sus exportaciones totales, el efecto es muy limitado, inferior al 0,9 por 100. Así por ejemplo, el veto afecta únicamente al 0,14 por 100 de las exportaciones españolas, al 0,05 por 100 de las exportaciones alemanas o al 0,05 por 100 de las exportaciones francesas.

Por último, el citado estudio del Parlamento Europeo no encuentra, hasta diciembre, impacto en el empleo en ningún país de la Unión.

La economía rusa ha salido peor parada, aunque no puede saberse si es por las sanciones (el estudio estima que éstas supondrán un coste para Rusia de 23 millardos de euros en 2014 y de 75 millardos en 2015), es posible que otras cuestiones, como la caída del precio del petróleo y gas, sus principales exportaciones, hayan desempeñado un papel mucho mayor. El comercio exterior ruso ha caído en un 30 por 100 en los dos primeros meses del año, y su comercio con la UE, más de un tercio. La inflación rusa alcanzó el 17 por 100 en marzo, la mayor tasa en 13 años.

\section{Medidas de compensación}

Tanto la Administración española como la Unión Europea han introducido medidas encaminadas a paliar los efectos del veto ruso.

Entre las medidas de la Administración española, destacan las siguientes. La Secretaría de Es- tado de Comercio ${ }^{7}$ ha desplegado además nuevas medidas para minimizar el impacto del veto ruso a las importaciones de productos de la Unión Europea, que afecta al sector agroalimentario español. Las medidas, algunas de acción inmediata y otras de cara al medio y largo plazo, son las siguientes:

- Aumento en un 50 por 100 de la aportación de ICEX a los Planes sectoriales de frutas y hortalizas para 2015: los planes, analizados conjuntamente con los sectores, tendrán por objetivo o bien mercados tradicionales de la exportación hortofrutícola española, o bien terceros mercados, atendiendo a los intereses y preferencias del sector.

- Congelación durante 2015 de las cuotas a pagar por las empresas agroalimentarias en las ferias de Pabellón Oficial organizadas por ICEX: se extiende el apoyo a todo el sector agroalimentario, que de forma directa o indirecta se ve afectado por las consecuencias de este veto.

- Financiación de visitas de inspectores de países terceros: mantenimiento o incremento, si fuera necesario, de los fondos específicos para la apertura de mercados que requieren visitas o inspecciones/auditorías in situ de las autoridades competentes y/o de las empresas que desean exportar.

- Intensificar el acercamiento de la oferta hortofrutícola española al sector importador mundial: se duplicó el apoyo económico de ICEX al Programa de Compradores Internacionales de la feria Fruit Attraction (Madrid, 15/17 de octubre de 2014) con el fin de traer mayor número de importadores. Se incrementarán el número de misiones de compradores y periodistas de países objetivo a zonas de producción españolas para que conozcan la oferta y puedan informar en el exterior de la alta calidad y variedad de los productos hortofrutícolas españoles.

\footnotetext{
7 http://www.mineco.gob.es/portal/site/mineco/menuitem.ac30f9

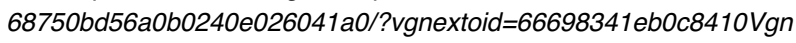
VCM1000001d04140aRCRD\&vgnextchannel $=864 \mathrm{e} 154527515310 \mathrm{~V}$ gnVCM1000001d04140aRCRD
} 
- Identificación de mercados alternativos: se está trabajando para identificar oportunidades de negocio en mercados alternativos donde focalizar esfuerzos (negociación de acuerdos sanitarios o fitosanitarios, actividades de promoción, mejora de la información de mercado...) en el marco del grupo de trabajo de frutas y hortalizas y el grupo cárnico.

- Potenciar la utilización de la base de datos de barreras comerciales de la Secretaría de Estado de Comercio, un instrumento muy eficaz en apoyo de los problemas específicos que afrontan las empresas en los mercados de países terceros.

- Actividades de información y formación: se tendrá especialmente en cuenta a los sectores afectados por el embargo ruso en las actividades de información y formación (estudios de mercado, seminarios sobre oportunidades de negocio en el exterior, conferencias, ...) que se lleven a cabo en la red periférica y exterior de la Secretaría de Estado de Comercio.

Por su parte, España, nada más conocer la prohibición rusa, se dirigió a la Comisión solicitando la aplicación de medidas urgentes en defensa del sector. La Comisión reaccionó rápidamente.

En un primer momento, el 11 de agosto, adoptó un primer paquete para productos en situación de crisis grave, aportando 32,7 millones de euros para melocotones y nectarinas, en crisis ya con anterioridad. Una semana más tarde, el 18 de agosto, se aprobaron 125 millones de euros para el resto de los sectores. Posteriormente, el 28 de agosto se aprueban 20 millones de euros para lácteos y quesos, y el 3 de septiembre, $60 \mathrm{mi}$ llones de euros (más otros 60 de fondos nacionales) para campañas de promoción.

Finalmente, el 30 de septiembre se estableció un nuevo programa de ayuda para las frutas y hortalizas afectadas por el embargo ruso por importe de 165 millones de euros. Esta cantidad no proviene en principio de la reserva de crisis, sino de diversos sobrantes de otras partidas consignadas en el ámbito de la Política Agrícola Común.
Este programa se divide en cuatro grupos de productos más o menos los mismos que el paquete anterior: manzanas y peras; cítricos (naranjas, clementinas y mandarinas); hortalizas (tomates, zanahorias, pimientos y pepinos) y otras frutas (kiwis, ciruelas y uvas de mesa). En función de las exportaciones medias de los tres últimos años se han asignado cantidades máximas a doce Estados miembros, para cada uno de estos grupos: España 94.600 toneladas; Italia, 77.270; Bélgica 59.430; Grecia 45.075; Francia, 31.050; Holanda, 29.000; Polonia, 18.750; Chipre, 16.220; Alemania, 13.100; Croacia, 8.950; Portugal, 4.345; y Hungría, 1.295 toneladas.

Como complemento a las medidas de apoyo de mercado adoptadas por la Comisión Europea, se lanzó una iniciativa específica para reforzar los esfuerzos para la apertura de nuevos mercados y aumentar la presencia de los productos comunitarios sujetos a prohibición por parte de Rusia.

El objetivo de esta iniciativa específica pretende movilizar apoyo a todos los niveles para solucionar las barreras identificadas que impiden o limitan el acceso de los productos comunitarios sujetos a veto a mercados de los terceros países identificados como prioritarios.

Los países identificados como prioritarios fueron doce (Brasil, China, Chile, Colombia, Perú, India, Indonesia, México, Turquía, Estados Unidos, Canadá y Vietnam). Para cada uno de ellos se identificó igualmente las barreras comerciales sobre las que se centrarán los esfuerzos. En lo que respecta a sectores/productos se cubre un espectro amplio que abarca los sectores cárnicos (avícola, vacuno y porcino), el sector lácteo y el sector de frutas y verduras frescas y procesadas.

\section{Conclusión}

En 2013, las exportaciones españolas a Rusia, del conjunto de productos agroalimentarios sobre los que recaerían, en agosto de 2014, las sanciones $\triangle$ 
rusas impuestas como represalia a los países que, a su vez, habían introducido sanciones a Rusia por sus actividades en Ucrania, alcanzaron los $338 \mathrm{mi}-$ llones de euros. Esta cantidad representa el 0,14 por 100 de las exportaciones españolas, pero determinados productos pueden verse muy afectados. Para ver el impacto sobre cada subsector se ha comparado el periodo desde la introducción del veto hasta la actualidad (agosto de 2004 hasta febrero de 2015), para ver si los productos que se han dejado de exportar a Rusia han podido encontrar otros mercados.

El resultado es que cuatro de los subsectores, carne, pescado, lácteos y preparados alimenticios, no han sufrido pérdidas significativas como consecuencia de las sanciones rusas de agosto de 2014 . Respecto a los dos sectores restantes, el comportamiento es dispar dependiendo de los subsectores. Uno de los que a priori podían resultar más afectado, el de los cítricos (el segundo mayor), ha reaccionado sorprendentemente bien, encontrando otras salidas para sus productos. El mayor de todos ellos, el de tomates, sí que ha visto reducir sus exportaciones, en una cuantía sólo ligeramente superior a la que sería explicada por el veto ruso. Otros dos sectores afectados, el del albaricoque y las demás frutas, han sufrido también fuertes caídas, pero el veto ruso no es suficiente factor explicativo suficiente para explicar su evolución, ya que las exportaciones a otros destinos han caído más (aunque no se puede descartar una relación de si estas exportaciones se reexportan posteriormente, con o sin una transformación). En el caso del albaricoque, dada su estacionalidad, habrá que esperar a los meses de mayo y junio para calibrar más precisamente los efectos.

\section{Bibliografía}

[1] KRAATZ, S. (2014). "The Russian Embargo: Impact on the Economic and Employment Situation in the EU". Parlamento Europeo Departamento A: Economía y Política Científica, PE 536.291. Recuperado de: http://www.europarl.europa.eu/RegData/etudes/BRIE/2014/536 291/IPOL_BRI(2014)536291_EN.pdf

[2] PEREIRA CASTAÑARES, J. C. (1993). «España y la U.R.S.S. en una Europa en transformación». Universidad Complutense de Madrid. Cuadernos de Historia Contemporánea $n^{\circ} 15$. Recuperado de: http://revistas.ucm.es/index.php/CHCO/article/ viewFile/CHCO9393110189A/7098. Recuperado de: http://ec.europa.eu/trade/policy/countriesand-regions/countries/russia/

[3] SÁNCHEZ ANDRÉS, A. (2006). «Las relaciones económicas entre España y Rusia». Madrid, Real Instituto Elcano. Revista ARI, $\mathrm{n}^{\circ} 4-2006$, 17/01/2006.

[4] SÁNCHEZ ANDRÉS, A. (2007). «Tendencias recientes del comercio de Rusia con España». Boletín Económico BICE, n 2.920, pp. 1-15.

[5] SÁNCHEZ ANDRÉS, A.; SHKOLYAR, N. y TEPERMAN, V. (2008). «La internacionalización de la empresa española. Estudio monográfico sobre el entorno económico y las oportunidades de inversión en: Rusia». Instituto Español de Comercio Exterior, Instituto de Crédito Oficial y Fundación Real Instituto Elcano. Recuperado de: http://www.realinstitutoelcano.org/wps/wcm/ connect/f9ac37004f01993d9723f73170baead1/ Monografia_Rusia_ICEX_ICO_RIE.pdf?MOD= AJPERES

[6] SHKOLYAR, N. A. (2008). «Rusia: Periodo de Crecimiento y Relaciones Económicas con España». Papeles del Este. Recuperado de: http://www.boe.es/doue/2014/229/L00001-00011. $p d f$ 


\begin{abstract}
ANEXO
Relación de países de destino de los subsectores más afectados por el veto ruso y cantidades exportadas a ellos después del mismo y en el periodo previo
\end{abstract}

\begin{tabular}{|c|c|c|c|c|}
\hline & \multicolumn{4}{|c|}{ Exportaciones } \\
\hline & AG12FB13 & AG13FB14 & AG14FB15 & $\begin{array}{c}\% \text { Varicion } \\
15 / 12\end{array}$ \\
\hline Rusia ....... & $81.280 .753,5$ & $2.626 .374,4$ & - & $-100,0$ \\
\hline Francia ....................... & $388.731 .791,3$ & $430.377 .560,8$ & $352.594 .587,5$ & $-9,3$ \\
\hline Portugal ....................... & $159.276 .345,9$ & $175.816 .789,6$ & $172.255 .595,2$ & 8,1 \\
\hline 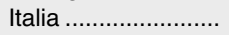 & $155.592 .213,5$ & $167.382 .768,2$ & $145.213 .364,1$ & $-6,7$ \\
\hline 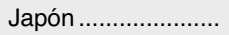 & $56.218 .115,6$ & $79.237 .024,3$ & $131.567 .591,1$ & 134,0 \\
\hline Corea del Sur ......... & $17.257 .631,2$ & $21.202 .826,6$ & $90.334 .781,7$ & 423,4 \\
\hline China ....................... & $43.353 .212,1$ & $53.703 .119,7$ & $80.888 .220,0$ & 86,6 \\
\hline Alemania .................... & $93.035 .726,3$ & $99.861 .894,1$ & $61.070 .669,2$ & $-34,4$ \\
\hline Reino Unido ............. & $53.131 .153,5$ & $70.475 .924,6$ & $48.090 .389,6$ & $-9,5$ \\
\hline Polonia ....................... & $33.803 .748,3$ & $62.701 .615,5$ & $44.562 .374,0$ & 31,8 \\
\hline República Checa ... & $27.363 .360,6$ & $40.759 .519,4$ & $33.824 .634,7$ & 23,6 \\
\hline Bulgaria...................... & $27.939 .190,4$ & $36.761 .764,7$ & $32.516 .148,4$ & 16,4 \\
\hline Países Bajos........... & $33.565 .693,0$ & $36.528 .683,1$ & $29.262 .662,7$ & $-12,8$ \\
\hline Dinamarca ................ & $35.036 .874,1$ & $32.301 .931,1$ & $28.776 .084,2$ & $-17,9$ \\
\hline Rumanía ................... & $14.625 .209,5$ & $21.357 .568,2$ & $21.839 .384,5$ & 49,3 \\
\hline Hong-Kong............... & $14.824 .023,7$ & $19.987 .424,4$ & $20.702 .982,3$ & 39,7 \\
\hline Bélgica ........................ & $26.068 .458,5$ & $20.054 .389,0$ & $18.280 .665,8$ & $-29,9$ \\
\hline 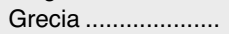 & $15.138 .000,3$ & $21.492 .843,1$ & $16.898 .274,5$ & 11,6 \\
\hline Eslovaquia ................ & $12.395 .935,9$ & $15.790 .573,4$ & $13.638 .796,3$ & 10,0 \\
\hline Serbia ....................... & $6.057 .125,9$ & $10.319 .556,3$ & $12.093 .578,0$ & 99,7 \\
\hline Filipinas..................... & $2.988 .207,8$ & $4.413 .762,1$ & $12.061 .855,4$ & 303,6 \\
\hline Hungría .................... & $11.293 .235,3$ & $10.421 .355,7$ & $10.451 .535,6$ & $-7,5$ \\
\hline Irlanda ....................... & $7.406 .056,5$ & $11.277 .939,3$ & $8.877 .307,9$ & 19,9 \\
\hline Singapur .................... & $3.953 .466,6$ & 4.155.992,6 & $8.542 .197,2$ & 116,1 \\
\hline Estados Unidos....... & $1.069 .002,1$ & $4.337 .012,9$ & 7.387.141,3 & 591,0 \\
\hline Montenegro................ & $2.202 .660,2$ & $4.102 .055,7$ & $6.759 .253,3$ & 206,9 \\
\hline Chipre ........................ & $7.624 .122,5$ & $2.250 .301,5$ & $6.519 .257,9$ & $-14,5$ \\
\hline Taiwán......................... & - & - & $6.169 .352,1$ & - \\
\hline Macedonia ............... & $5.051 .130,6$ & $4.441 .771,7$ & $5.188 .186,3$ & 2,7 \\
\hline Sudáfrica................... & $3.423 .815,2$ & $1.260 .223,5$ & $4.445 .238,9$ & 29,8 \\
\hline Nueva Zelanda ...... & - & - & $4.311 .751,9$ & - \\
\hline Angola........................ & $1.844 .211,5$ & $1.416 .341,8$ & $4.175 .269,4$ & 126,4 \\
\hline Uruguay ..................... & $205.065,1$ & $566.107,9$ & $4.141 .583,9$ & $1.919,6$ \\
\hline 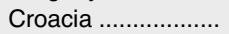 & $5.642 .867,0$ & $4.621 .614,6$ & $3.775 .904,9$ & $-33,1$ \\
\hline Austria........................ & $4.370 .109,0$ & $3.971 .060,2$ & $3.655 .705,0$ & $-16,3$ \\
\hline Georgia .................... & $216.270,3$ & $575.021,9$ & $3.623 .573,8$ & $1.575,5$ \\
\hline Kirguizistán ............. & - & - & $3.609 .666,9$ & - \\
\hline Suecia ....................... & $3.555 .762,1$ & $4.180 .493,4$ & $3.482 .555,6$ & $-2,1$ \\
\hline Canadá ....................... & $26.017,7$ & $941.849,5$ & $2.930 .361,5$ & $11.163,0$ \\
\hline Eslovenia ................... & $2.566 .603,3$ & $4.441 .085,6$ & $2.768 .858,9$ & 7,9 \\
\hline Cuba .......................... & - & $197.242,5$ & $2.382 .779,5$ & - \\
\hline TOTAL ........................ & $1.391 .684 .730,8$ & $1.515 .069 .622,3$ & $1.498 .805 .172,6$ & 7,7 \\
\hline
\end{tabular}




\begin{tabular}{|c|c|c|c|}
\hline \multicolumn{4}{|c|}{$\begin{array}{l}0202 \text { CARNE DE ANIMALES DE LA ESPECIE BOVINA, } \\
\text { FRESCA O CONGELADA }\end{array}$} \\
\hline & \multicolumn{3}{|c|}{ Exportaciones } \\
\hline & AG13FB14 & AG14FB15 & \% Variación \\
\hline Rusia & $5.579 .641,4$ & - & $-100,0$ \\
\hline Portugal ............................. & $12.915 .228,5$ & $12.958 .092,9$ & 0,3 \\
\hline Francia........................... & $10.540 .314,3$ & $10.673 .566,1$ & 1,3 \\
\hline 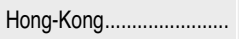 & $702.247,0$ & $5.642 .295,4$ & 703,5 \\
\hline Países Bajos ........................ & $3.426 .944,6$ & $4.522 .318,9$ & 32,0 \\
\hline Reino Unido .......................... & $2.997 .370,3$ & $4.350 .198,2$ & 45,1 \\
\hline Marruecos.......................... & $2.770 .011,2$ & $3.547 .780,0$ & 28,1 \\
\hline Alemania & $2.903 .629,7$ & $3.508 .018,3$ & 20,8 \\
\hline Italia & $709.483,1$ & $3.080 .748,0$ & 334,2 \\
\hline 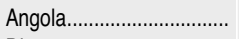 & $439.921,1$ & $904.215,0$ & 105,5 \\
\hline Dinamarca .......................... & $121.850,1$ & $848.613,8$ & 596,4 \\
\hline Gabón .................................. & - & $792.506,5$ & - \\
\hline Bulgaria............................ & $838.059,4$ & $784.107,7$ & $-6,4$ \\
\hline 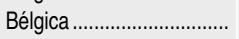 & $673.785,6$ & $767.365,2$ & 13,9 \\
\hline Malta & $790.888,2$ & $716.263,3$ & $-9,4$ \\
\hline 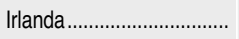 & $844.935,8$ & $667.465,3$ & $-21,0$ \\
\hline República Checa ............... & $755.916,5$ & $631.942,0$ & $-16,4$ \\
\hline Chipre ............................. & $785.587,8$ & $578.910,0$ & $-26,3$ \\
\hline 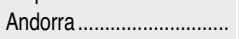 & $599.321,0$ & $462.178,8$ & $-22,9$ \\
\hline Kazajstán ............................. & - & $408.829,9$ & - \\
\hline 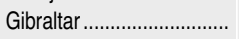 & $214.359,9$ & $287.630,4$ & 34,2 \\
\hline Uzbekistán ........................... & - & $282.302,3$ & - \\
\hline Estonia & - & $233.258,8$ & - \\
\hline 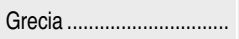 & $442.721,8$ & $229.274,3$ & $-48,2$ \\
\hline Montenegro & - & $169.359,0$ & - \\
\hline Finlandia ............................. & $169.153,0$ & $157.666,0$ & $-6,8$ \\
\hline TOTAL & $50.602 .402,9$ & $59.169 .872,8$ & 16,9 \\
\hline
\end{tabular}

\begin{tabular}{|c|c|c|c|}
\hline \multicolumn{4}{|c|}{0303 PESCADO CONGELADO (EXCEPTO LOS DE LA 0304) } \\
\hline & \multicolumn{3}{|c|}{ Exportaciones } \\
\hline & AG13FB14 & AG14FB15 & \% Variación \\
\hline Rusia .................................... & $1.071 .094,0$ & - & $-100,0$ \\
\hline Portugal ........................... & $75.153 .088,0$ & $70.574 .254,2$ & $-6,1$ \\
\hline 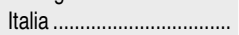 & $39.644 .839,9$ & $37.420 .627,0$ & $-5,6$ \\
\hline 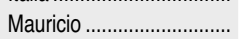 & $43.335 .886,7$ & $32.495 .073,5$ & $-25,0$ \\
\hline Ecuador ............................. & $25.650 .106,9$ & $29.139 .662,1$ & 13,6 \\
\hline Vietnam................................ & $9.801 .655,5$ & $24.994 .364,8$ & 155,0 \\
\hline Seychelles ......................... & $34.759 .849,6$ & $22.430 .983,9$ & $-35,5$ \\
\hline Costa de Marfil .................... & $3.843 .137,6$ & $18.892 .908,0$ & 391,6 \\
\hline China & $14.837 .417,2$ & $13.110 .515,4$ & $-11,6$ \\
\hline 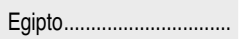 & $2.960 .629,9$ & $9.170 .971,4$ & 209,8 \\
\hline 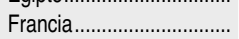 & $7.419 .667,0$ & $8.788 .216,2$ & 18,4 \\
\hline 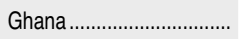 & $2.201 .832,2$ & $8.420 .302,3$ & 282,4 \\
\hline 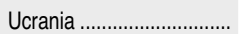 & $6.736 .390,0$ & $8.026 .345,9$ & 19,1 \\
\hline 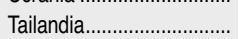 & $19.294 .619,6$ & $7.845 .690,0$ & $-59,3$ \\
\hline Madagascar ........................ & $13.313 .094,9$ & $7.621 .158,7$ & $-42,8$ \\
\hline 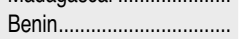 & $1.023 .833,0$ & $6.021 .045,3$ & 488,1 \\
\hline 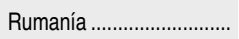 & $2.665 .431,4$ & $5.469 .791,4$ & 105,2 \\
\hline 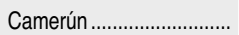 & $14.301 .781,4$ & $5.458 .440,2$ & $-61,8$ \\
\hline Grecia & $5.473 .262,3$ & $5.395 .430,2$ & $-1,4$ \\
\hline 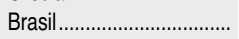 & $3.757 .075,4$ & $4.319 .416,0$ & 15,0 \\
\hline 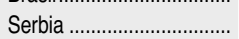 & $3.001 .547,4$ & $3.964 .911,7$ & 32,1 \\
\hline 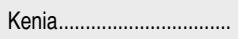 & $1.207 .042,8$ & $3.806 .183,1$ & 215,3 \\
\hline El Salvador ........................... & $11.625 .856,3$ & $3.542 .882,9$ & $-69,5$ \\
\hline Japón & $3.285 .788,6$ & $3.489 .065,8$ & 6,2 \\
\hline 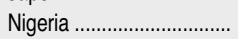 & $735.820,4$ & $3.386 .086,2$ & 360,2 \\
\hline Corea del Sur ..................... & $2.863 .034,8$ & $3.285 .995,4$ & 14,8 \\
\hline TOTAL & $415.270 .285,0$ & $400.646 .850,8$ & $-3,5$ \\
\hline
\end{tabular}

\begin{tabular}{|c|c|c|c|c|c|c|c|}
\hline \multicolumn{4}{|c|}{07020000 TOMATES FRESCOS O REFRIGERADOS } & \multicolumn{4}{|c|}{0707 PEPINOS Y PEPINILLOS, FRESCOS } \\
\hline & \multicolumn{3}{|c|}{ Exportaciones } & & \multicolumn{3}{|c|}{ Exportaciones } \\
\hline & AG13FB14 & AG14FB15 & \% Variación & & AG13FB14 & AG14FB15 & \% Variación \\
\hline Rusia .............................. & $27.459 .407,1$ & - & $-100,0$ & Rusia .............................. & 12.153.877,7 & - & $-100,0$ \\
\hline Alemania............................ & $148.449 .642,2$ & $146.346 .940,8$ & $-1,4$ & Alemania............................ & $135.731 .631,0$ & $123.996 .436,7$ & $-8,6$ \\
\hline Reino Unido ........................ & $86.174 .428,0$ & $83.431 .103,2$ & $-3,2$ & Países Bajos....................... & $59.229 .402,3$ & $51.729 .556,4$ & $-12,7$ \\
\hline Francia ............................. & $78.029 .243,9$ & $78.811 .695,6$ & 1,0 & Reino Unido....................... & $44.435 .947,3$ & $41.280 .634,9$ & $-7,1$ \\
\hline Países Bajos....................... & $97.321 .640,9$ & $70.611 .081,3$ & $-27,4$ & 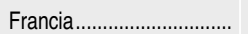 & $27.111 .974,6$ & $27.785 .151,2$ & 2,5 \\
\hline Polonia & $33.696 .000,5$ & $38.839 .580,5$ & 15,3 & Polonia & $19.438 .230,6$ & $17.099 .319,7$ & $-12,0$ \\
\hline 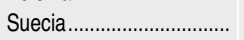 & $20.488 .392,1$ & $22.287 .314,3$ & 8,8 & Suecia................................... & $16.233 .499,6$ & $15.309 .878,4$ & $-5,7$ \\
\hline 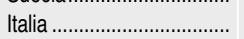 & $18.188 .661,9$ & $22.084 .392,7$ & 21,4 & 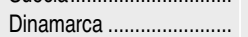 & $11.454 .217,2$ & $9.484 .037,6$ & $-17,2$ \\
\hline Bélgica .................................. & $17.060 .436,9$ & $14.992 .612,3$ & $-12,1$ & República Checa .............. & $7.611 .908,9$ & $8.815 .383,7$ & 15,8 \\
\hline Lituania ............................... & $6.581 .879,2$ & $13.925 .951,7$ & 111,6 & Austria.............................. & $7.824 .970,5$ & $5.335 .620,2$ & $-31,8$ \\
\hline República Checa .............. & $14.548 .777,7$ & $12.761 .924,2$ & $-12,3$ & Suiza & $5.207 .687,3$ & $4.950 .750,7$ & $-4,9$ \\
\hline 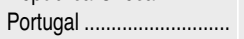 & $8.820 .593,1$ & $10.097 .335,4$ & 14,5 & Bélgica .................................. & $5.517 .296,9$ & $4.784 .628,5$ & $-13,3$ \\
\hline 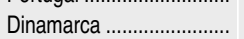 & $9.225 .892,6$ & $9.876 .329,1$ & 7,1 & Italia & $4.486 .117,9$ & $3.932 .505,9$ & $-12,3$ \\
\hline Finlandia .............................. & $8.781 .703,9$ & $8.929 .769,6$ & 1,7 & Lituania ................................. & $3.588 .999,5$ & $3.856 .660,2$ & 7,5 \\
\hline Suiza ................................... & $7.857 .698,0$ & $7.983 .980,1$ & 1,6 & Noruega ................................. & $3.874 .581,8$ & $2.743 .704,9$ & $-29,2$ \\
\hline Austria............................ & $9.294 .801,3$ & $7.133 .486,3$ & $-23,3$ & 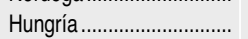 & $1.799 .413,1$ & $2.308 .685,5$ & 28,3 \\
\hline Rumanía ................................ & $3.914 .615,9$ & $6.110 .902,2$ & 56,1 & Letonia .............................. & $1.917 .833,7$ & $2.160 .924,6$ & 12,7 \\
\hline 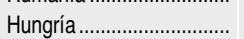 & $3.785 .034,1$ & $5.639 .756,0$ & 49,0 & 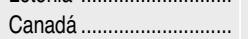 & $1.791 .167,3$ & $2.131 .791,8$ & 19,0 \\
\hline Letonia ............................... & $4.969 .309,2$ & $5.427 .026,6$ & 9,2 & Eslovaquia ......................... & $2.406 .564,2$ & $1.796 .446,5$ & $-25,4$ \\
\hline 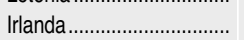 & $4.209 .392,3$ & $3.625 .550,7$ & $-13,9$ & 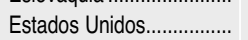 & $892.793,0$ & $1.496 .412,1$ & 67,6 \\
\hline 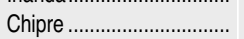 & $981.121,7$ & $3.611 .657,2$ & 268,1 & 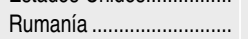 & $1.456 .929,3$ & $1.475 .768,5$ & 1,3 \\
\hline Eslovaquia ........................... & $2.781 .200,0$ & $3.457 .877,8$ & 24,3 & 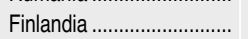 & $2.460 .431,7$ & $1.312 .416,8$ & $-46,7$ \\
\hline Noruega & $2.821 .424,8$ & $2.366 .848,4$ & $-16,1$ & 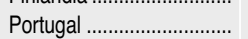 & $1.212 .417,1$ & $1.275 .481,8$ & 5,2 \\
\hline Bulgaria................................... & $594.563,0$ & $1.314 .713,5$ & 121,1 & 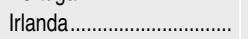 & $757.115,3$ & $803.772,0$ & 6,2 \\
\hline 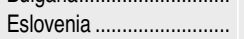 & $467.551,7$ & $1.194 .116,3$ & 155,4 & 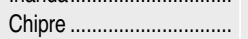 & $373.490,4$ & $629.320,1$ & 68,5 \\
\hline Croacia & $723.828,2$ & $791.309,0$ & 9,3 & Bulgaria............................ & $621.904,4$ & $601.054,2$ & $-3,4$ \\
\hline TOTAL & $621.908 .794,1$ & $584.712 .800,2$ & $-6,0$ & TOTAL & $381.855 .864,3$ & $338.455 .371,3$ & $-11,4$ \\
\hline
\end{tabular}


EFECTOS DEL VETO RUSO EN LAS EXPORTACIONES ESPAÑOLAS

\begin{tabular}{|c|c|c|c|}
\hline \multicolumn{4}{|c|}{0709 LAS DEMÁS HORTALIZAS, FRESCAS } \\
\hline & \multicolumn{3}{|c|}{ Exportaciones } \\
\hline & AG13FB14 & AG14FB15 & \% Variación \\
\hline 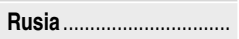 & $9.404 .996,7$ & $16.709,5$ & $-99,8$ \\
\hline Alemania................................ & $234.374 .996,3$ & $241.576 .460,5$ & 3,1 \\
\hline Francia & $160.624 .018,0$ & $172.804 .048,9$ & 7,6 \\
\hline Reino Unido ....................... & $94.267 .895,7$ & $108.287 .603,3$ & 14,9 \\
\hline 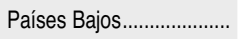 & $107.688 .600,7$ & $104.338 .411,1$ & $-3,1$ \\
\hline 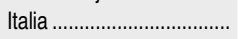 & $52.927 .644,5$ & $54.873 .063,8$ & 3,7 \\
\hline Polonia & $29.313 .291,5$ & $28.475 .694,8$ & $-2,9$ \\
\hline 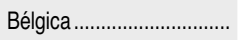 & $24.575 .692,3$ & $24.842 .672,9$ & 1,1 \\
\hline 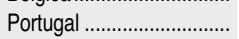 & $13.607 .094,5$ & $17.496 .693,4$ & 28,6 \\
\hline Suecia & $14.851 .553,2$ & $15.765 .306,6$ & 6,2 \\
\hline 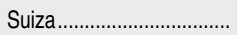 & $14.927 .450,1$ & $15.686 .606,2$ & 5,1 \\
\hline 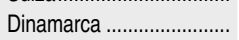 & $13.020 .797,9$ & $11.448 .086,8$ & $-12,1$ \\
\hline República Checa .............. & $8.674 .403,4$ & $10.954 .677,8$ & 26,3 \\
\hline 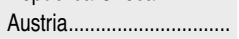 & $10.221 .806,2$ & $8.905 .023,1$ & $-12,9$ \\
\hline Lituania & $2.965 .293,9$ & $8.415 .345,1$ & 183,8 \\
\hline 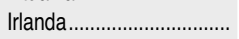 & $5.337 .662,7$ & $5.788 .115,0$ & 8,4 \\
\hline Estados Unidos.................. & $1.977 .826,7$ & $5.720 .885,7$ & 189,3 \\
\hline 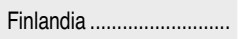 & $6.331 .606,3$ & $5.492 .747,6$ & $-13,2$ \\
\hline 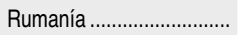 & $3.863 .781,0$ & $5.154 .377,5$ & 33,4 \\
\hline Noruega & $4.520 .849,3$ & $4.469 .208,8$ & $-1,1$ \\
\hline Canadá ................................. & $3.582 .462,1$ & $4.462 .614,0$ & 24,6 \\
\hline 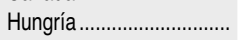 & $2.645 .478,4$ & $3.680 .814,3$ & 39,1 \\
\hline Letonia & $2.035 .155,1$ & $3.090 .788,5$ & 51,9 \\
\hline 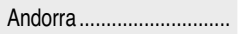 & $2.237 .409,8$ & $2.435 .800,5$ & 8,9 \\
\hline 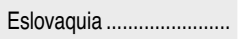 & $2.243 .362,9$ & $2.209 .448,8$ & $-1,5$ \\
\hline Croacia & $1.116 .061,4$ & $1.332 .602,0$ & 19,4 \\
\hline TOTAL & $833.815 .338,8$ & $873.583 .006,2$ & 4,8 \\
\hline
\end{tabular}

\begin{tabular}{|c|c|c|c|}
\hline \multicolumn{4}{|c|}{$\begin{array}{l}0802 \text { LOS DEMÁS FRUTOS DE CÁSCARA: ALMENDRAS, } \\
\text { AVELLANAS, NUECES }\end{array}$} \\
\hline & \multicolumn{3}{|c|}{ Exportaciones } \\
\hline & AG13FB14 & AG14FB15 & \% Variación \\
\hline 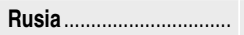 & $1.936 .815,8$ & 23,2 & $-100,0$ \\
\hline Alemania & $61.636 .963,9$ & $104.065 .410,6$ & 68,8 \\
\hline 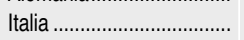 & $78.799 .445,7$ & $98.494 .292,7$ & 25,0 \\
\hline Francia........................... & $51.684 .236,4$ & $67.618 .023,8$ & 30,8 \\
\hline Estados Unidos................. & $12.066 .238,4$ & $23.735 .015,1$ & 96,7 \\
\hline 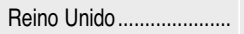 & $13.562 .001,8$ & $23.270 .835,2$ & 71,6 \\
\hline 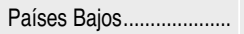 & $11.927 .359,0$ & $17.250 .576,0$ & 44,6 \\
\hline Portugal .................. & $17.303 .302,7$ & $16.193 .429,6$ & $-6,4$ \\
\hline 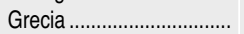 & $6.851 .957,1$ & $12.014 .485,2$ & 75,3 \\
\hline 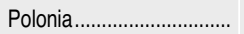 & $8.630 .296,0$ & $9.704 .217,0$ & 12,4 \\
\hline 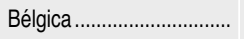 & $10.689 .588,0$ & $9.673 .711,7$ & $-9,5$ \\
\hline 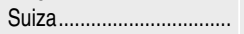 & $8.651 .618,1$ & $8.368 .614,9$ & $-3,3$ \\
\hline República Checa .............. & $5.009 .628,3$ & $7.511 .615,8$ & 49,9 \\
\hline 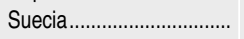 & $4.043 .598,1$ & $5.329 .219,0$ & 31,8 \\
\hline 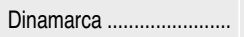 & $1.630 .244,1$ & $3.191 .210,2$ & 95,8 \\
\hline Austria........................... & $3.498 .955,8$ & $2.512 .327,2$ & $-28,2$ \\
\hline Turquía.................................. & $59.770,0$ & $2.140 .916,8$ & $3.481,9$ \\
\hline 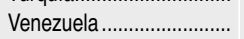 & $579.999,8$ & $1.957 .182,0$ & 237,4 \\
\hline Canadá & $420.386,2$ & $1.631 .498,6$ & 288,1 \\
\hline Lituania .............................. & $1.256 .018,9$ & $1.628 .086,8$ & 29,6 \\
\hline 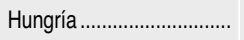 & $956.108,4$ & $1.586 .969,3$ & 66,0 \\
\hline 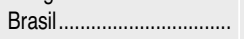 & $1.728 .755,8$ & $1.541 .996,7$ & $-10,8$ \\
\hline Taiwán................................. & $166.266,6$ & $1.215 .005,8$ & 630,8 \\
\hline Líbano & $1.801 .059,3$ & $1.100 .686,0$ & $-38,9$ \\
\hline 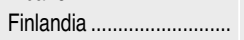 & $1.426 .875,3$ & $1.068 .153,2$ & $-25,1$ \\
\hline Eslovaquia ........................ & $1.355 .586,9$ & $1.034 .190,6$ & $-23,7$ \\
\hline TOTAL & $321.850 .299,0$ & $434.395 .688,6$ & 35,0 \\
\hline
\end{tabular}

\begin{tabular}{|c|c|c|c|c|c|c|c|}
\hline \multicolumn{4}{|c|}{0805 CÍTRICOS } & \multicolumn{4}{|c|}{0809 ALBARICOQUES, MELOCOTONES, CEREZAS } \\
\hline & \multicolumn{3}{|c|}{ Exportaciones } & & \multicolumn{3}{|c|}{ Exportaciones } \\
\hline & AG13FB14 & AG14FB15 & \% Variación & & AG13FB14 & AG14FB15 & \% Variación \\
\hline 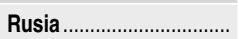 & $22.989 .046,6$ & $116.870,3$ & $-99,5$ & Rusia .............................. & 18.764.119,7 & 2.013.720,3 & $-89,3$ \\
\hline Alemania............................ & $511.007 .639,6$ & $559.925 .018,9$ & 9,6 & Alemania............................ & $80.268 .821,0$ & $66.939 .977,2$ & $-16,6$ \\
\hline Francia ................................. & $416.321 .233,5$ & $468.947 .454,2$ & 12,6 & Reino Unido ....................... & $43.776 .150,1$ & $43.361 .122,0$ & $-0,9$ \\
\hline Reino Unido ....................... & $156.341 .138,0$ & $154.863 .049,1$ & $-0,9$ & Francia................................... & $50.030 .263,4$ & $40.244 .631,9$ & $-19,6$ \\
\hline 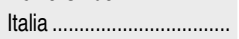 & $88.668 .948,2$ & $120.090 .168,1$ & 35,4 & Italia ......................................... & $25.478 .977,6$ & $25.231 .655,5$ & $-1,0$ \\
\hline 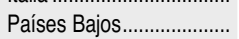 & $126.024 .572,0$ & $119.463 .252,7$ & $-5,2$ & 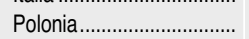 & $22.432 .087,3$ & $19.947 .602,5$ & $-11,1$ \\
\hline 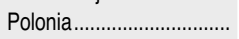 & $123.867 .648,5$ & $119.237 .582,9$ & $-3,7$ & 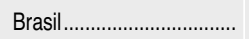 & $17.377 .114,3$ & $17.823 .700,8$ & 2,6 \\
\hline 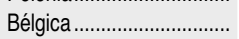 & $63.703 .155,9$ & $66.057 .155,8$ & 3,7 & Países Bajos...................... & $21.846 .556,3$ & $13.220 .204,7$ & $-39,5$ \\
\hline 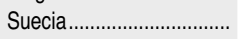 & $40.663 .349,7$ & $44.231 .364,3$ & 8,8 & 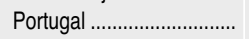 & $20.196 .257,2$ & $11.708 .671,3$ & $-42,0$ \\
\hline República Checa .............. & $38.425 .072,0$ & $41.480 .650,8$ & 8,0 & Bélgica ............................... & $16.181 .411,2$ & $9.757 .677,1$ & $-39,7$ \\
\hline Suiza & $38.271 .132,2$ & $39.353 .894,3$ & 2,8 & 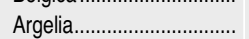 & $4.521 .937,4$ & $6.687 .453,4$ & 47,9 \\
\hline 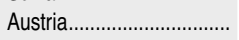 & $36.087 .664,2$ & $36.533 .615,2$ & 1,2 & 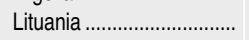 & $1.739 .647,7$ & $4.352 .053,0$ & 150,2 \\
\hline Estados Unidos.................... & $42.571 .430,6$ & $35.121 .926,2$ & $-17,5$ & Hungría ............................. & $756.329,4$ & $2.789 .256,3$ & 268,8 \\
\hline 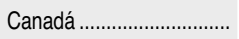 & $18.157 .974,4$ & $27.342 .935,7$ & 50,6 & 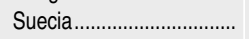 & $2.765 .061,9$ & $2.564 .614,3$ & $-7,2$ \\
\hline Dinamarca ......................... & $29.338 .176,2$ & $26.830 .336,7$ & $-8,5$ & Bielorrusia........................... & $2.528 .844,1$ & $2.542 .115,9$ & 0,5 \\
\hline 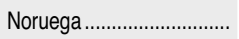 & $28.319 .887,8$ & $24.343 .629,7$ & $-14,0$ & 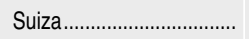 & $2.608 .091,9$ & $2.287 .996,9$ & $-12,3$ \\
\hline 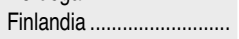 & $18.872 .454,5$ & $19.080 .646,5$ & 1,1 & República Checa ............. & $3.633 .194,5$ & $2.159 .254,6$ & $-40,6$ \\
\hline 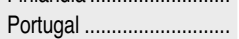 & $14.283 .221,1$ & $17.017 .913,5$ & 19,1 & 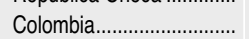 & $1.639 .955,2$ & $1.932 .271,6$ & 17,8 \\
\hline 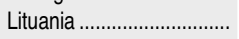 & $12.047 .002,8$ & $14.932 .480,8$ & 24,0 & 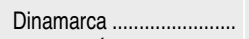 & $2.431 .844,9$ & $1.780 .478,9$ & $-26,8$ \\
\hline 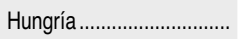 & $11.077 .311,6$ & $14.849 .578,4$ & 34,1 & Emiratos Árabes Unidos.. & $2.992 .932,3$ & $1.617 .403,5$ & $-46,0$ \\
\hline 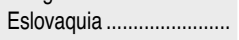 & $11.280 .665,7$ & $11.844 .608,1$ & 5,0 & 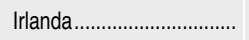 & $1.107 .431,2$ & $1.586 .106,9$ & 43,2 \\
\hline 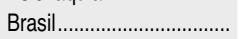 & $8.949 .199,7$ & $9.931 .390,6$ & 11,0 & Letonia ................................ & $1.550 .440,5$ & $1.496 .272,4$ & $-3,5$ \\
\hline 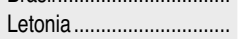 & $7.083 .809,0$ & $9.064 .851,4$ & 28,0 & 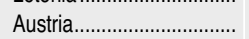 & $1.064 .403,3$ & $1.455 .934,4$ & 36,8 \\
\hline 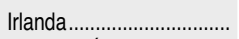 & $6.790 .643,2$ & $9.019 .527,8$ & 32,8 & Arabia Saudí...................... & $1.963 .330,2$ & $1.375 .124,7$ & $-30,0$ \\
\hline Emiratos Árabes Unidos.. & $6.213 .834,6$ & $8.616 .044,0$ & 38,7 & 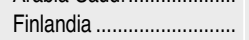 & $1.292 .822,8$ & $780.493,0$ & $-39,6$ \\
\hline 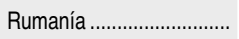 & $4.190 .713,6$ & $6.245 .063,4$ & 49,0 & Sudáfrica............................... & $545.740,5$ & $692.945,3$ & 27,0 \\
\hline TOTAL & $1.920 .467 .243,8$ & $2.049 .785 .826,1$ & 6,7 & TOTAL ............................... & $356.900 .790,4$ & $293.561 .928,8$ & $-17,7$ \\
\hline
\end{tabular}




\section{Juan José Otamendi García-Jalón}

0810 LAS DEMÁS FRUTAS: FRESAS, FRAMBUESAS

\begin{tabular}{|c|c|c|c|}
\hline & \multicolumn{3}{|c|}{ Exportaciones } \\
\hline & AG13FB14 & AG14FB15 & \% Variación \\
\hline 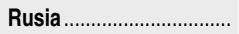 & $18.550 .538,3$ & - & $-100,0$ \\
\hline 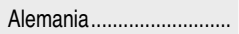 & $144.300 .901,0$ & $88.466 .187,1$ & $-38,7$ \\
\hline Reino Unido ..................... & $73.717 .157,8$ & $77.061 .425,6$ & 4,5 \\
\hline 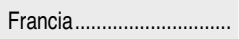 & $73.555 .911,1$ & $52.147 .435,4$ & $-29,1$ \\
\hline Italia & $65.899 .176,7$ & $40.995 .294,5$ & $-37,8$ \\
\hline Países Bajos....................... & $39.309 .688,4$ & $34.819 .315,6$ & $-11,4$ \\
\hline 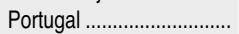 & $14.797 .810,6$ & $18.065 .006,1$ & 22,1 \\
\hline 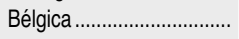 & $15.559 .165,1$ & $12.584 .225,9$ & $-19,1$ \\
\hline 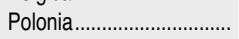 & $22.035 .830,9$ & $10.614 .377,8$ & $-51,8$ \\
\hline 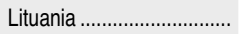 & $16.316 .006,2$ & $8.809 .453,6$ & $-46,0$ \\
\hline 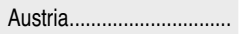 & $15.747 .126,3$ & $6.603 .226,5$ & $-58,1$ \\
\hline Bielorrusia .............................. & $4.070 .820,4$ & $6.341 .685,2$ & 55,8 \\
\hline República Checa ............... & $12.703 .833,1$ & $5.833 .806,2$ & $-54,1$ \\
\hline 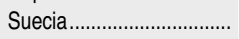 & $7.384 .852,9$ & $5.020 .471,1$ & $-32,0$ \\
\hline 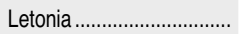 & $9.794 .505,1$ & $4.597 .875,1$ & $-53,1$ \\
\hline 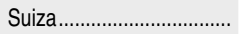 & $4.717 .096,8$ & $4.281 .573,4$ & $-9,2$ \\
\hline 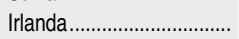 & $2.448 .756,7$ & $3.724 .038,0$ & 52,1 \\
\hline Estados Unidos.................... & $2.790 .213,5$ & $2.841 .667,8$ & 1,8 \\
\hline Emiratos Árabes Unidos.. & $1.897 .872,1$ & $2.822 .037,7$ & 48,7 \\
\hline 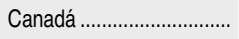 & $1.855 .719,3$ & $2.721 .230,1$ & 46,6 \\
\hline Marruecos........................... & $1.432 .106,3$ & $2.603 .084,1$ & 81,8 \\
\hline 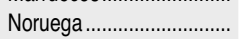 & $1.979 .431,4$ & $2.528 .782,5$ & 27,8 \\
\hline 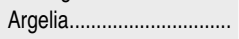 & $1.831 .691,2$ & $2.351 .879,3$ & 28,4 \\
\hline Dinamarca .......................... & $3.712 .919,2$ & $2.307 .457,3$ & $-37,9$ \\
\hline 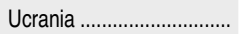 & $1.893 .675,5$ & $1.848 .455,9$ & $-2,4$ \\
\hline Brasil.................................. & $1.551 .416,6$ & $1.787 .744,1$ & 15,2 \\
\hline$\ldots \ldots \ldots \ldots . .$. & $583.232 .823,6$ & $417.992 .539,7$ & $-28,3$ \\
\hline
\end{tabular}

